Journal Of Al Azhar University Engineering Sector

Vol. 12, No. 44, July, 2017, 907-931

\title{
A 2D NUMERICAL AND EXPERIMENTAL INVESTIGATION ON THE PRESSURE FLUCTUATIONS INSIDE A DOUBLE VOLUTE CENTRIFUGAL PUMP AT THREE DIFFERENT RADIAL GAPS
}

\author{
Ahmed S. Mansour and H. A. Abotaleb \\ Faculty of Engineering, Ain Shams University, Mechanical Power Department,
}

\begin{abstract}
Pressure fluctuations in centrifugal pumps are one of the most traumatic issues that exist as a result of the interaction between the rotor "impeller" and stator "volute". The experiments that were carried out on the double volute pump model in Saudi Arabia have proved that the radial gap "clearance" between the impeller and the tongue of the volute plays a major role in increasing and decreasing that vibrations that are generated due to the pressure fluctuations. Unsteady 2D simulations were carried out on the model to study the pressure fluctuations especially at the critical locations such as around the impeller, the cutwater, and the volute tongue. The results show that the sliding mesh technique is a very useful procedure for simulating these kinds of simulations. The results also show that the peak of the pressure fluctuations occurs at the first blade passing frequency for the 3 gaps "2, 3.6, 7"mm. Numerical static pressure was captured accurately for each gap but the amplitude of the pressure fluctuations were overestimated due to the inaccurate nature of the $2 \mathrm{D}$ simulations. The highest gap " $7 \mathrm{~mm}$ " is the best solution for the vibrations and noise reduction due to the decrease in the pressure fluctuations without affecting the performance of the pump greatly. The performance curves are discussed.
\end{abstract}

\section{INTRODUCTION}

Pressure fluctuations in centrifugal pumps can cause many problems. There are two major problems can occur due to this unsteady fluctuations, the first problem is the vibration of the pump that exceeds the acceptable limit as was mentioned by AtiaKhalifa, Amro Al-Qutub and YehiaKhulief [1]. Computational fluid dynamics became a very useful tool at the last years especially in fluid dynamics field. Experimental measurements are still very important to validate the numerical results against them to rightly understand the physical phenomena. Researchers carried out many 2D and 3D numerical simulations on the centrifugal pumps to validate the numerical results against the experimental data through the last decades. A. Khalifa, R. BenMansour, and A. Al-Qutub[2] investigated the double volute centrifugal pump "our current work" experimentally and validated the results numerically by FLUENT solver to study the effect of the radial gap on pressure field, vibrations, and noise especially at off-operating conditions. Increasing the radial gap decreases the vibrations and the noise to an acceptable limit without affecting the performance greatly. Decreasing the gap increases the vibrations so it is not recommended. Atia E. Khalifa. Amro M. Al-Qutub, and Rached Ben-Mansour [3] carried out a wide experimental investigation on the same pump model. They changed the rotating speed and the flow rate on the same original gap $3.6 \mathrm{~mm}$ and they concluded that the optimizing the 
clearance between the volute tongue and the impeller is required to overcome these problems. A.Al-Qutub, A. Khalifa, and Y. Khulief [4] investigated the same double volute pump but they used a V-cut blade impeller and another impeller without V-cut to study their effect on the vibrations of the pump. The results showed that using a V-cut blade decreases the vibrations to a good level without affecting the performance badly. Also they investigated increasing the radial gap that showed also decreasing the vibration and noise. Atia E. Khalifa [5] investigated the same pump but using impeller trimming method to reach many gaps. The impeller radius was trimmed by reducing it by 1,2 , and $3 \mathrm{~mm}$. The results showed that increasing the gap by this technique reduces the vibrations without affecting the performance badly but it was shown that this method is more effective at flow rates higher than the design flow rate or equal to it. Kean Wee Cheah, Thong See Lee and Sonny H. Winoto [6] carried out unsteady analysis of impeller-volute interaction in centrifugal pump. They used k-e model in FLUENT CFD package. The results showed that the impeller blade position relative to the tongue is responsible for the periodically pressure fluctuations. José González and Carlos Santolaria [7] carried out an unsteady 3D numerical simulation on a centrifugal pump and compared the results with the experimental data. They used sliding mesh technique in FLUENT CFD package. The numerical results showed that the loading of the blades has a relation to the torque "as a function of the relative position of the impeller" and the different pressure patterns has a relation to the secondary flow in the volute. They also showed that the major driven mechanism that establishes the features of the flow both in the volute and impeller is the pressure forces. Houlin Liu, Xianfang Wu, and Minggao Tan [8] investigated pressure fluctuations, the performance, hydraulically generated vibration, and level of noise. These fields of investigations are due to the effect of the width of the impeller on them. They used the combined CFD/FEM/BEM coupling method and the other was the combined CFD/FEM analysis for structure vibration. The last was for the structure vibration. It was shown that there were insignificant influences of the sound pressure of centrifugal pump on the structure. Mohan LamloumiHedi, KanfoudiHatem, ZgolliRidha [9] carried out a 3D numerical model and the SST model "Shear Stress Transport" and URANS equations were used for capturing the transient pressure fluctuations. The temporal behavior of internal flow was allowed to be accessed and the influence of mesh and condition limits were compared. A radial thrust was shown by the fields of velocity and pressure. A. G. Backman, M.J. Cervantes, and A.R. Zobeiri [10] used the commercial CFD package Ansys CFX to study the pressure fluctuations inside a pump turbine due to rotor-stator interaction. K- $\varepsilon$ turbulent model was used for solving incompressible URANS equations. Xiaoran Zhao, Zhengwei Wang, Yexiang Xiao, Yongyao Luo, Lei Cao [11] carried out 3D unsteady simulations on a centrifugal pump at off peak conditions to study the pressure pulsations characteristics. Lei Cao, Zhengwei Wang, Yexiang Xiao, and Yongyao Luo [12] investigated a centrifugal pump especially the clearance flows in the sidewall gaps that are considered as a source of noise and vibrations inside the pump due to their unsteadiness like the impeller and volute flow. The concluded that modifying the axial gaps affects the pressure fluctuations inside the pump. Houlin Liu, Xianfang Wu, and Minggao Tan [13] studied the unsteady flow inside a centrifugal pump at shut-off condition by solving the model numerically using URANS turbulence equations model. The major target of the investigation was to study the pressure fluctuations inside the pump and validate the results of particle image velocimetry (PIV). They used a high quality unstructured grid that is suitable for the turbulence model. Pei Ji, WANG Wenjie, and YUAN Shouqi [14] investigated the centrifugal pump flow numerically using SST k- $\omega$ turbulence model and found that the fluctuations of the pressure at the trailing edge are the highest near the tongue and on the pressure side. Alfred Fontanals, Alfredo Guardo, Miguel Coussirat and Eduard Egusquiz [15] investigated an entire stage in a centrifugal pump to study the pressure fluctuations inside the pump due to the rotorstator interaction. Fully turbulence simulations were carried out using URANS equations. R. Spence and J. Amaral-Teixeira [16] investigated a double entry double volute centrifugal pump to study the pressure pulsation inside it. They made a parametric study and the parameters were the sidewall clearance, snubber gap, vane arrangement, and the cutwater gap. The effect of the 
cutwater gap and the vane arrangements was the greatest across the 15 different monitored locations and the range of the flow. The results of the pressure fluctuations helped the researchers to give recommendations for the designers. R. Spence, J. Amaral-Teixeira [17] carried out a transient investigation on a centrifugal pump numerically and validated the results against the measurements at the 15 monitored locations inside the pump at the top dead center of the volute casing of the pump to better simulate the pulsation inside the pump than the discharge monitoring. C. G. Rodriguez, E. Egusquiza I. F. Santos studied the rotor-stator interaction inside a centrifugal pump - turbine. They carried out a theoretical analysis for explaining and predicting the amplitudes and the frequencies that are related to the strong interaction between the rotor and stator inside the machine. There was a single in the amplitude in the interactions for instance due to a problem in the guide vane. For vibration levels reduction, a drill was made in this vane and it was an effective solution. Shijie Guo and Yoshiyuki Maruta [19] experimentally investigated the pressure fluctuations inside a centrifugal pump with severely vaned diffusers. They found that the resonance can be excited when the impeller natural frequency coincidence with the sideband frequencies. M. Zhang and Tsukamoto [20] developed a computational and an experimental study on a centrifugal pump to investigate the interaction between the impeller and the vaned diffuser which has the same number of the vanes like the impeller. They found that the fluid forces on the combinations of vane numbers are lower than the forces on the fluid forces on the impeller with the same number of vanes as the vanes diffuser. Hong Wang and Hiroshi Tsukamoto conducted an experimental and a numerical study on a centrifugal pump to investigate pressure fluctuations. Wang and Tsukamoto [21] conducted an experimental study and a numerical investigation on a diffuser pump at off-design conditions. They found an asymmetric separation bubble near the pressure surface of the vane of the impeller. They also found a rotating stall in the passage of the impeller at lower flow rates (lower than $83 \%$ of the nominal flow rate) and also this rotating stall occurred at the diffuser passage as well which caused characteristic problems. Jose' Gonza'lez, Joaqui'nFerna'ndez, Eduardo Blanco, Carlos Santolaria [22] investigated the interaction between the rotor and stator inside a centrifugal pump experimentally and numerically by FLUENT CFD commercial package. Sliding mesh technique was used for the investigation. They studied the pressure fluctuations and the blade passing frequency because the effects of the unsteady flow are dependent on the flow rate at the blade passing frequency. H. Wang and H. Tsukamoto [23] carried out a 2D numerical investigation on a diffuser pump to investigate the pressure fluctuations inside the machine. They used Petrov-Galerkin method to get the solution and apply the boundary conditions in the integral form. They validated the calculated results against the experimental ones and the validation gave a good agreement. Blanco-Marigorta, Eduardo; Fernández-Francos, Joaquín González-Pérez, José; Santolaria-Morros, Carlos [24] investigated a 3D commercial centrifugal pump using the sliding mesh technique in fluent. They studied the pressure variation inside the pump at different flow rates due to the impeller- volute interaction. Kevin A. Kaupert and Thomas Staubli [25] investigated the unsteady pressure field of a high specific speed double spiral volute centrifugal pump. The results showed that the pressure fluctuations increases as the volume flux is further removed from the BEP and getting more near the interaction of the rotor-stator "at the trailing edge". M. Morgenroth and D. S. Weaver [26] studied the noise that was generated from a centrifugal pump in a connected piping system. They studied the effects of modifying the cutwater geometry and they used a semi empirical model for the acoustic standing waves separation from hydraulic pressure fluctuations. R. Dong, S. Chu and J. Katz [27] used particle image velocimetry PIV, noise, and pressure measurements for studying the modifications to impeller and volute tongue in a centrifugal pump. They found that the noise is due to the tongue oscillations and this is dependent on the tongue stiffness. John P. Pembroke, Eugene P., and David E. Littlefield [28] investigated a double suction cooling water pump to study the noise source. They found that the separation in the suction nozzle caused a flow distortion at the eye of the impeller is the source of the noise. So, they minimized the separation of the flow by developing a unique guide ring. They used CFD tools to validate the numerical results against the measurements. Jorge L. Parrondo-Gayo, Jose' Gonza'lez-Pe'rez, 
and Joaqui'nFerna'ndez-Francos [29] conducted an experimental investigation on a conventional centrifugal pump and studied the unsteady pressure distribution of the volute at flow rates from $0 \%$ to $160 \%$ of the BEP. The measurements was to adjust the parameters of a simple pump volute acoustic model. The role of the tongue in the impeller-volute interaction was clear from the experimental results and its responsibility for the sound generation. J.L. Parrondo, J. Fernandez, C. Santolaria\& J. Gonzalez [30] studied the interaction between the rotor-stator in an industrial centrifugal pump. They measured the pressure at some locations of the volute casing. At the blade passing frequency, they gave an attention to the pressure fluctuations with a regard to the amplitude and phase delay relative to a reference point. The flow rate and the location along the volute are main parameters that affect the pressure fluctuations and this indicates that the tongue affects the interaction inside the pump and the increase in the dynamic forces acting on the impeller in off-peak conditions. D. Croba and J. L. Kueny [31] developed a 2D numerical model to study the sources of vibrations of a centrifugal pump to reduce it. They used k- $\varepsilon$ turbulence model and a multi-domain overlapping grid technique to match the rotating impeller relative flow field and the stationary absolute one of the volute together and validated the results of the numerical model against the measurements and the validation gave a good agreement. Ken Atkins and Jim Tison [32] investigated the vibration problems of six centrifugal pumps and found that the source of vibrations was identified as an acoustic resonance of the pump internals excited by the BPF. To overcome this problem, they changed the impeller vanes because it was a simpler solution compared to the other solutions. R. D. Flack, S. M. Miner, and R. J. Beaudoin [33] measured the turbulence profile in a centrifugal pump. The turbulence intensity were different according to the position and the flow rate. N. Arndt, A. J. Acosta, C. E. Brennen, T. K. Caughey [34] investigated a laboratory centrifugal pump with different vaned diffusers by a 2D numerical solution. They generated a steady and an unsteady solution of the impeller. They studied the rotor-stator interaction and they found the largest pressure fluctuations on the impeller blades and the diffuser vanes were the same order of magnitude as the total pressure rise across the pump. They found also that increasing the vanes of the diffuser decreases the pressure fluctuations of the impeller blades. N. Arndt, A. J. Acosta, C. E. Brennen, T. K. Caughey [35] investigated the interaction between the rotor and stator of a centrifugal pump at different shaft speeds, flow coefficients, and radial gaps between impeller blades trailing edge and diffuser vanes leading edge.

\section{EXPERIMENTAL SET-UP}

The test rig was installed in the laboratory of King Fahd university of petroleum and minerals. The experiments were carried out on the single stage double volute centrifugal boiler feed pump model that was modeled using the reverse engineering program. The 0.4 scale factor was selected for the model manufacture to be suitable for the instrumentation and carrying out the experiments. According to [2], the diameter of the impeller is $142 \mathrm{~mm}$. The blade exit angle is 22.50. Three different gaps were investigated (the original gap $3.6 \mathrm{~mm} 2.5 \%$ of the impeller diameter), $2 \mathrm{~mm}$, and $7 \mathrm{~mm}$. The lower and higher gaps were achieved by trimming the volute tongue and lengthening it. The radial gap is the clearance between the impeller and the volute tongue and the impeller and the cut water. To dynamically balance the impeller, they used a twoplane machine to eliminate the unbalance of the rotor as a vibration source. The rotating speed is $3540 \mathrm{rpm}$ at $60 \mathrm{~Hz}$. The standard 4 inches orifice meter was used for measuring the flow rate. For measuring the pressure drop across the orifice, they used a differential pressure transducer (PDCR 4170, 700 mbar, +/- 0.08\% FS accuracy). The researchers also connected the pump model to a water loop and a gate valve controlled the flow rate at the discharge side. To measure the pressure pulsations and the static pressure, nine dynamic pressure transducers of the type Omega's DPX101-250 were placed 1mm within the volute plexiglass cover plate at different angular positions to measure the unsteady pressure pulsations "fluctuations" inside the pump model. The coordinates of the measuring positions are given in table 1. One pressure transducers was placed at the discharge pipe and another one was placed at the suction pipe. Some sensors 
were located around the impeller symmetrically for static and dynamic pressure investigation. They were installed relative to the volute tongue. measuring sensors number 2,3,4 are as the same as 5,7, and 9 geometrically. The sensors were installed at $1 \mathrm{~mm}$ from the wall of the experimental model.

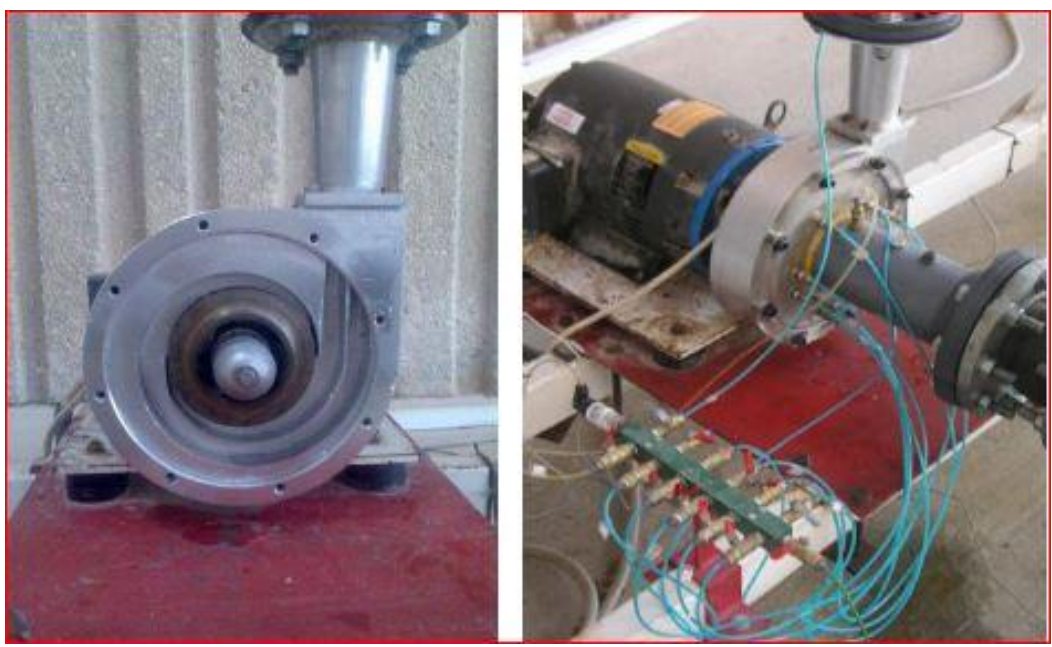

Fig.1 The test rig of the pump model with the measurement sensors of pressure.

\section{Mathematical Modeling}

Computational fluid dynamics CFD is considered to be one of the most effective tools in the field of solving many practical flow problems. Fluid mechanics and understanding the flow behavior inside turbomachinery are very complex. CFD tools such as the writing a code or using the commercial packages such as Ansys FLUENT or CFX are very useful to be used for understanding the flow behavior by building a model "The CAD process", then generating the solution domain "The mesh generation", and then studying the numerical solution. 2D simulations are considered easy to be designed and analyzed, but they are not accurate due to taking into consideration 2 axes of freedom of the flow and this is not realistic. The 2D simulations were carried out to investigate the flow behavior inside the double volute centrifugal pump as a try to understand the sources of vibrations inside it as a result from the rotor-stator interaction. The main targets of the simulations are: study the unsteady static pressure distribution, the pressure fluctuations that are considered to be the main source of vibrations that generate noise and an unaccepted unbalance at off-peak operating conditions, and calculating the Fast Fourier Transform (FFT) to study the effect of changing the radial gap and the flow rate on the energy of the pulsations that are reflected to the pump vibration. Also, the velocity vectors will show us the behavior of the flow at different gaps and flow rates to know the best design that reduces the vibrations especially at the interaction zone and the critical locations (the cutwater and the volute tongue). According to [2], 2D simulations were carried out on the original gap (3.6 $\mathrm{mm}$ ) and $7 \mathrm{~mm}$. Mesh dependence study were conducted. 75,000 cells were selected to be the optimum number of elements with the required refinement at the critical locations" Volute tongue, blade tip, interfaces, and cutwater". The size of the cells at these zones captured the pressure fluctuations successfully. The pressure fluctuations were calculated peak-to-peak to get the amplitude of the pressure fluctuations. That's why we followed the same technique of meshing to get the predicted results of the current 2D simulations. The experiments showed that the 1st blade passing frequency (BPF) is the frequency at which the highest vibrations energy occur. Small sidebands were generated at the 2 nd and 3 rd blade passing frequency. The validation of the FFT magnitudes were consistent with the measurements. So, we have carried out another mesh dependence study on the 2D impeller mesh, one mesh with 1st layer distance $0.25 \mathrm{~mm}$ and another mesh with $0.15 \mathrm{~mm} 1$ st layer distance. The cells with $0.25 \mathrm{~mm}$ distance from the blade 

PUMP AT THREE DIFFERENT RADIAL GAPS

surface is $0.25 \mathrm{~mm}$ have successfully captured the static pressure and the pressure fluctuations. So, we completed the other simulations with $0.25 \mathrm{~mm}$ as a first layer thickness.

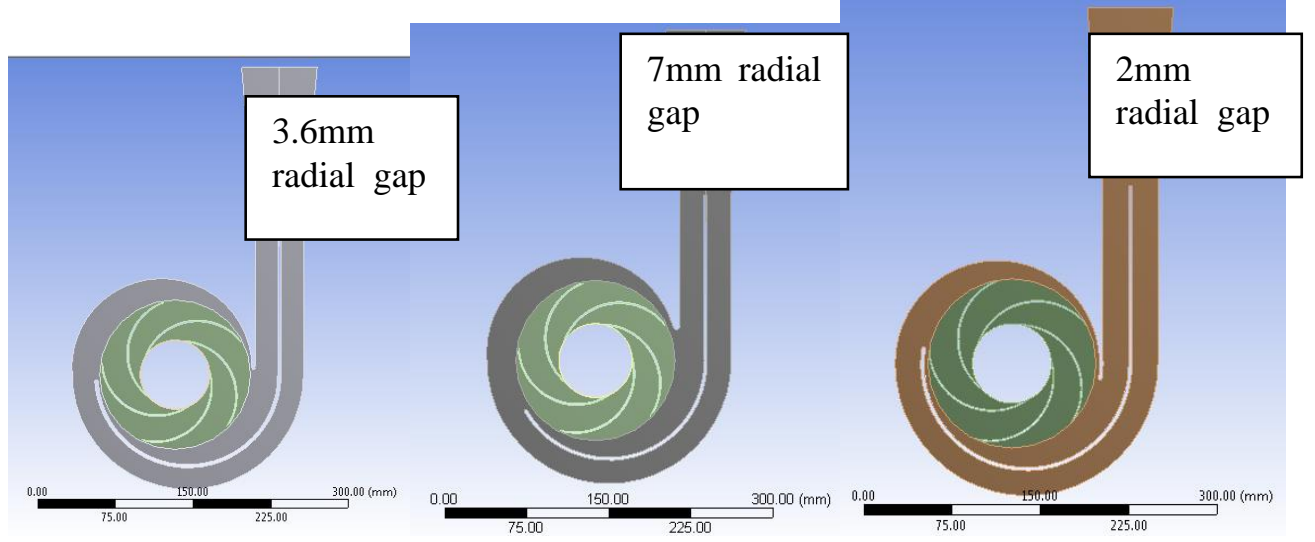

Fig.2 The 2D geometry of the pump model at different gaps

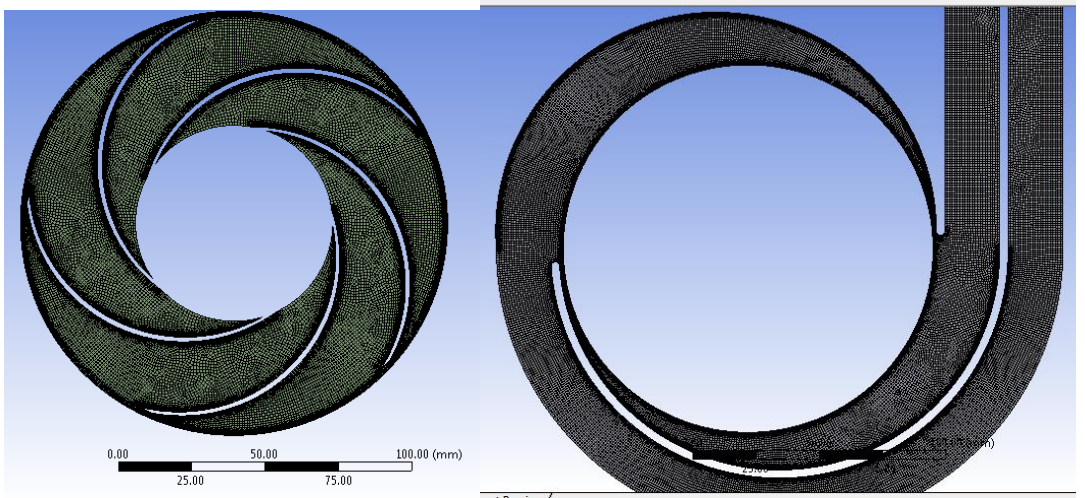

Fig.3 The rotor and stator mesh with the refined cells at 3.6mm gap
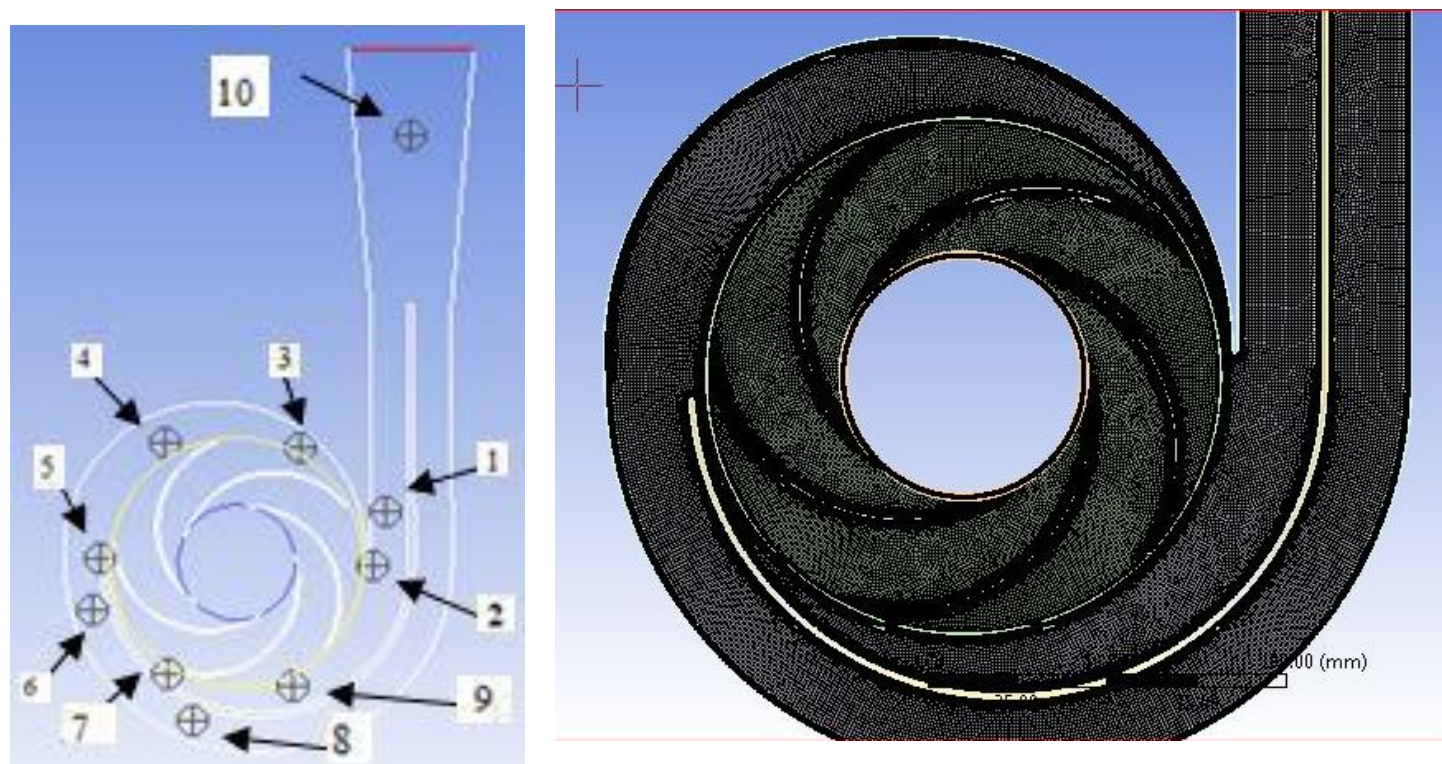

Fig.4 The 2D mesh assembly at "3.6 mm gap" that was generated by Ansys mesher and the monitor locations 


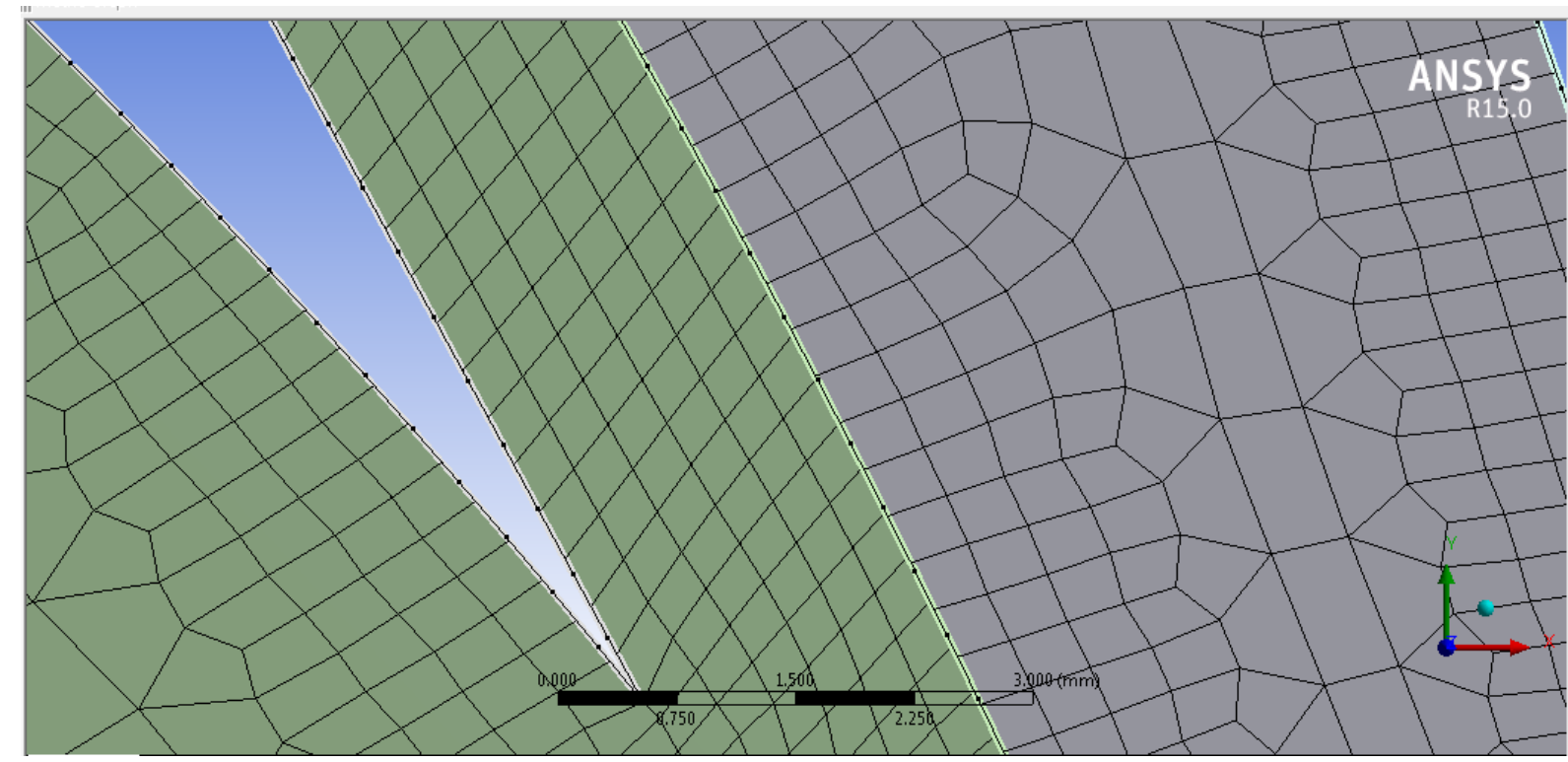

Fig.5 The refinement process around the blade's tip and the interface between the rotor and stator

Table 1 The coordinates of monitoring locations 2D and 3D. Another 10 points at the same (x,y) locations but are located at the impeller mid plane were also monitored

\begin{tabular}{|c|c|c|c|c|c|c|c|c|c|c|}
\hline Location & 1 & 2 & 3 & 4 & 5 & 6 & 7 & 8 & 9 & 10 \\
\hline $\mathrm{x}[\mathrm{mm}]$ & 85.1 & 77.95 & 37.33 & -40.5 & -78.95 & -83.2 & -39.66 & -25.11 & 32.52 & 100 \\
\hline $\mathrm{y}[\mathrm{mm}]$ & 29.3 & -2.73 & 67.34 & 70.15 & 2.76 & -28.64 & -66 & -93.7 & -73.08 & 250 \\
\hline
\end{tabular}

Sliding mesh technique was used in [2] and also in the current work for the 2D simulations. Sliding mesh method is on e of the best techniques that are suitable for our study due to the strong rotor-stator interaction. Full unsteady turbulent model should be used due to the high turbulent nature of the fluid inside the pump. That's why we selected standard $\mathrm{k}-\varepsilon$ model in FLUENT . This special model has proved that it is very helpful for our study because we do not have to use more accurate models that requires higher mesh accuracy such as y+ to be lower than 1. According to [6], they used different kinds of turbulence models and they found that the results did not change greatly. So, we directly used standard k- $\varepsilon$ model specially [2] used it and the results were pretty good. Unsteady Navier-Stokes were solved, eddy viscosity approach was used for modeling Reynolds stresses.

\section{The continuity equation:}

$\frac{\partial \rho}{\partial t}+\nabla \cdot(\vec{V})=\mathbf{0}$

The conservation of momentum equation:

$\frac{\partial(\rho \vec{V})}{\partial t}+\nabla \cdot(\rho \vec{V} \vec{V})=-\nabla P+\nabla \cdot(\bar{\tau})+\rho \vec{g}$

$\overline{\bar{\tau}}$ is the stress tensor $=\mu[(\nabla \vec{V}+\vec{\nabla} \nabla)], P$ is the static pressure, and $\rho \vec{g}$ is the gravitational body force. where $\mu$ is the kinematic viscosity,

The transport equations are:

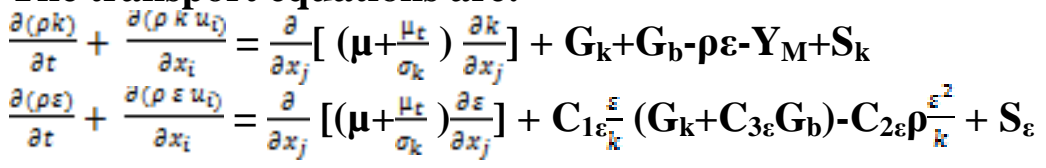


The constant of the model are $C_{1 \varepsilon}, C_{2 \varepsilon}$ and $C_{3 \varepsilon}$ and the turbulent Prandtl numbers for $K$ and $\varepsilon$. $S_{k}$ and $S_{\varepsilon}$ are user defined terms. Due to mean velocity gradients, there is a generation of turbulent kinetic energy and $G_{k}$ represents it.

$\mathbf{G}_{\mathbf{k}}=-\boldsymbol{\rho} \overline{u_{1}^{s} u_{j}^{s}} \frac{\partial\left(u_{j}\right)}{\partial x_{i}}$

And also Boussinesq's method $\quad G_{k}=\mu_{t} S^{2}$

$\mathbf{S}$ is the modulus of the mean rate of strain tensor $\mathbf{S}=\sqrt{2 S_{i j} S_{i j}}$

The bouyancy generates turbulence kinetic energy $\mathbf{G}_{\mathbf{b}}=\boldsymbol{\beta} \mathbf{g}_{i_{P_{t}}} \frac{\mu t}{\partial x_{i}}$

$\operatorname{Pr}_{t}$ is the Prandtl number for energy and $g_{i}$ is the gravitational vector in the $i^{\text {th }}$ direction. $\operatorname{Pr}_{t}$ has a default value 0.85 in the standard $k-\varepsilon$ model.

The coefficient of thermal expansion is calculated from $\beta=-\frac{1}{p}\left(\frac{\partial p}{\partial T}\right)_{p}$

If $\mathbf{G b}>0$ turbulent kinetic energy tends to be increased in unstable stratisfaction.

For stable behaviour, the buoyancy Gb has to be lower than 0 to suppress the turbulence. The generation of $\mathrm{K}$ by the buoyancy will be included if at gravity field and the temperature field are non-zero.

In the $\varepsilon$ transport equation, if $\mathbf{G b}=0$, the buoyancy effects on $\varepsilon$ will be neglected by default. To calculate $\mathrm{C} 3 \varepsilon$ we use $\mathrm{C} 3 \varepsilon=\tanh \left|\frac{\mathrm{v}}{\mathrm{u}}\right|$

$u$ is the component of the flow velocity perpendicular to the gravitational vector and $v$ is the componet of the flow velocity parallel to the gravitational vector. For buoyant shear layers that are perpendicular to the gravitational vector $\mathrm{C} 3 \varepsilon$ will become 0 .

Turbulent viscosity is calculated from $\mu_{\mathrm{t}}=\rho \mathrm{C} \mu \frac{\mathrm{k}^{2}}{\mathrm{z}} \quad \mathrm{C} \boldsymbol{\mu}=0.09$

The contribution of the fluctuating dilatation in compressible turbulence to the overall dissipation rate is represented by YM. It is zero because we use water" incompressible fluid". Sliding mesh means that the cell zones slide relative to one another along the grid interface in discrete steps. (impeller rotates relative to the stationary volute).

3.1 Boundary conditions

\begin{tabular}{|c|c|c|}
\hline Q/Qn & $\begin{array}{l}\text { Velocity } \\
\text { Inlet }[\mathrm{m} / \mathrm{s}]\end{array}$ & $\begin{array}{l}\text { Pressure } \\
\text { Outlet } \\
{[\mathrm{KPa}]}\end{array}$ \\
\hline 1 & 3.2 & 290 \\
\hline 0.75 & 2.4 & 345 \\
\hline 0.5 & 1.6 & 375 \\
\hline 0.25 & 0.8 & 395 \\
\hline
\end{tabular}

Table 2 The 2D

boundary conditions.

The 2D simulations were carried out to study the pressure fluctuations inside the pump that are generated due to the strong rotor-stator interaction. Different flow rates were studied and the appropriate boundary conditions were used for the validation. FLUENT 15 solver commercial package was used for carrying out the 2D simulation . According to [2] Qn is the nominal flow rate. The rotational velocity is $3540 \mathrm{rpm}$ and the outlet static pressure was measured at the laboratory. The researchers calculated the inlet velocity based on the measured flow rate and averaged area between the hub and shroud. The impeller diameter was taken as the radial distance that is equal to the vane's leading edge mid height. The static pressure was monitored at the critical locations and it was calculated by the area weighted 
average method in Fluent. Two different time steps were used "0.0001-0.00001" sec according to [2]. Both time steps gave the same results. That's why we carried out our $2 \mathrm{D}$ simulations using 0.0001 sec as a time step. The previous and the current $2 \mathrm{D}$ numerical results were validated against the experimental measuremnts and the validation was good and proved that the 1st BPF is the dominant frequency where the highest FFT (Fast Fourier Transform) magnitude occurs at it. The same setup procedure in FLUENT was followed, second order implicit in time with 50 iteration per time step were used and second order upwind for momentum and turbulence kinetic energy were used. Standard discretization for pressure was used and simple scheme was used. Ten surface monitors were created in FLUENT at the locations that are identical in their 2D coordinates with the sensors locations to see the unsteady static pressure while the simulation is running and then the values used for FFT calculations by a MATLAB code. The rotating speed is 3540 rpm.

\section{Results and discussions}

4.1The 2D Mesh Independence:

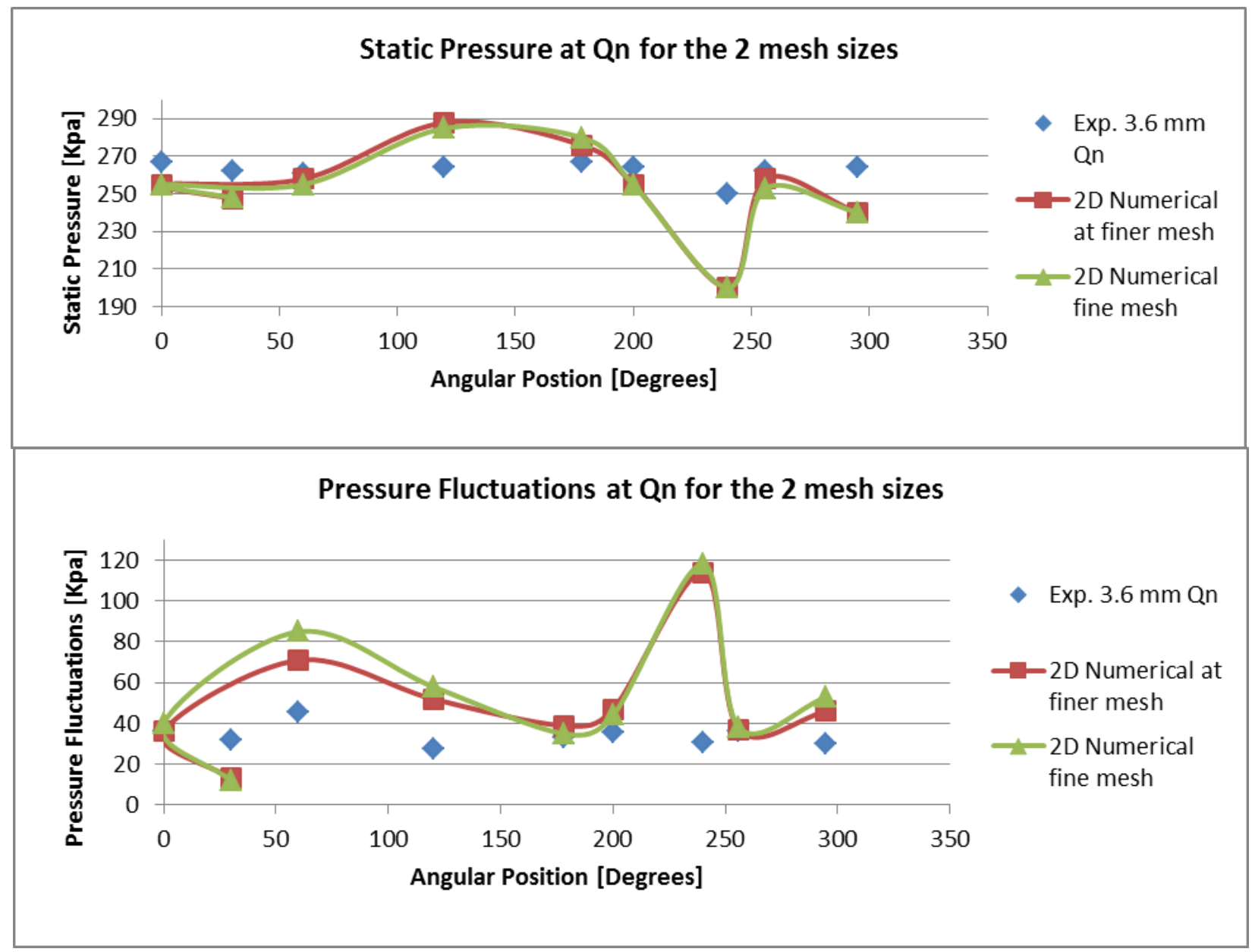

Fig.6 The difference between the values of the fine and the finer mesh are considered negligible 
A 2D NUMERICAL AND EXPERIMENTAL INVESTIGATION ON THE PRESSURE FLUCTUATIONS INSIDE A DOUBLE VOLUTE CENTRIFUGAL PUMP AT THREE DIFFERENT RADIAL GAPS

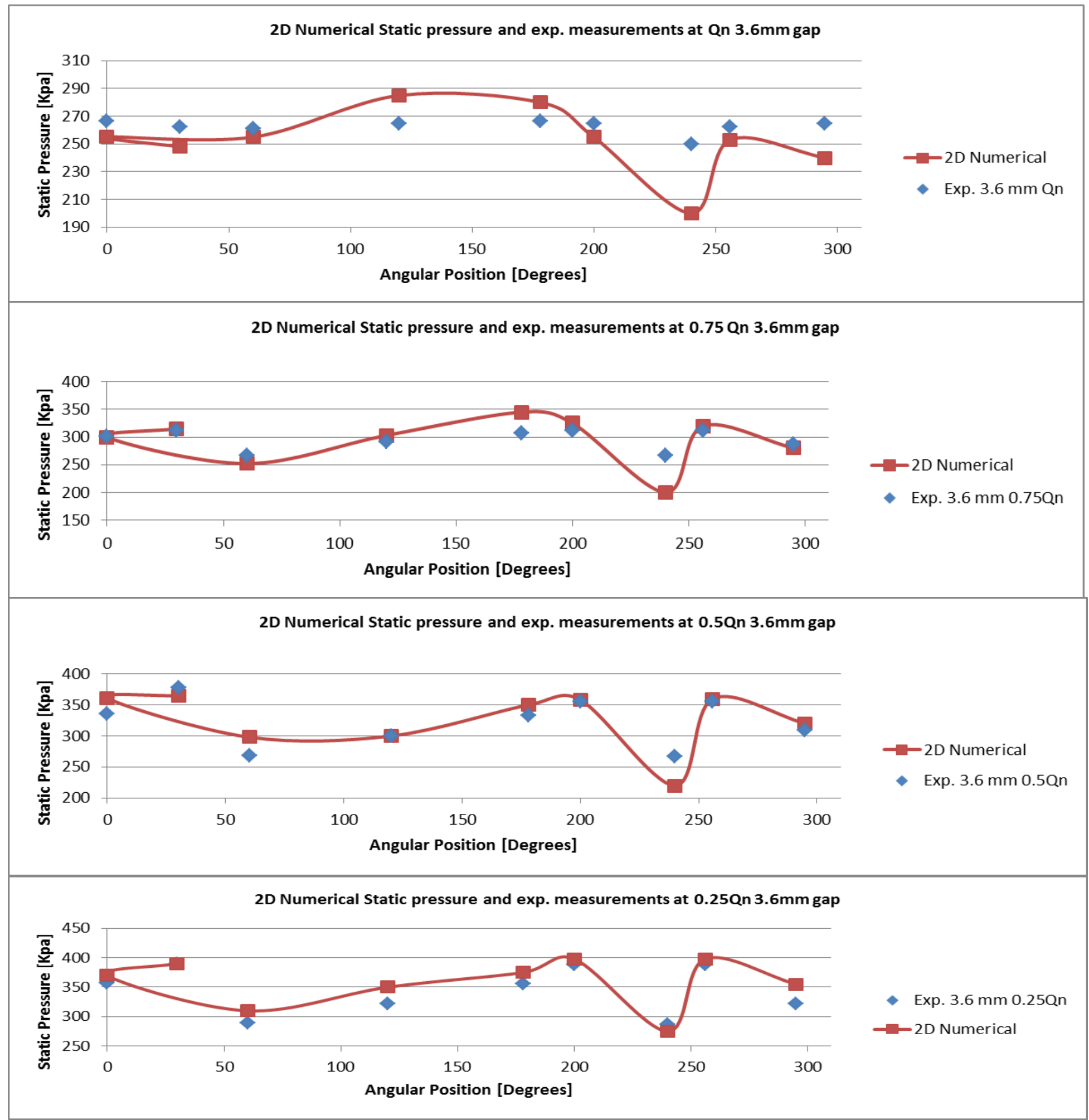

Fig.7 
A 2D NUMERICAL AND EXPERIMENTAL INVESTIGATION ON THE PRESSURE FLUCTUATIONS INSIDE A DOUBLE VOLUTE CENTRIFUGAL PUMP AT THREE DIFFERENT RADIAL GAPS

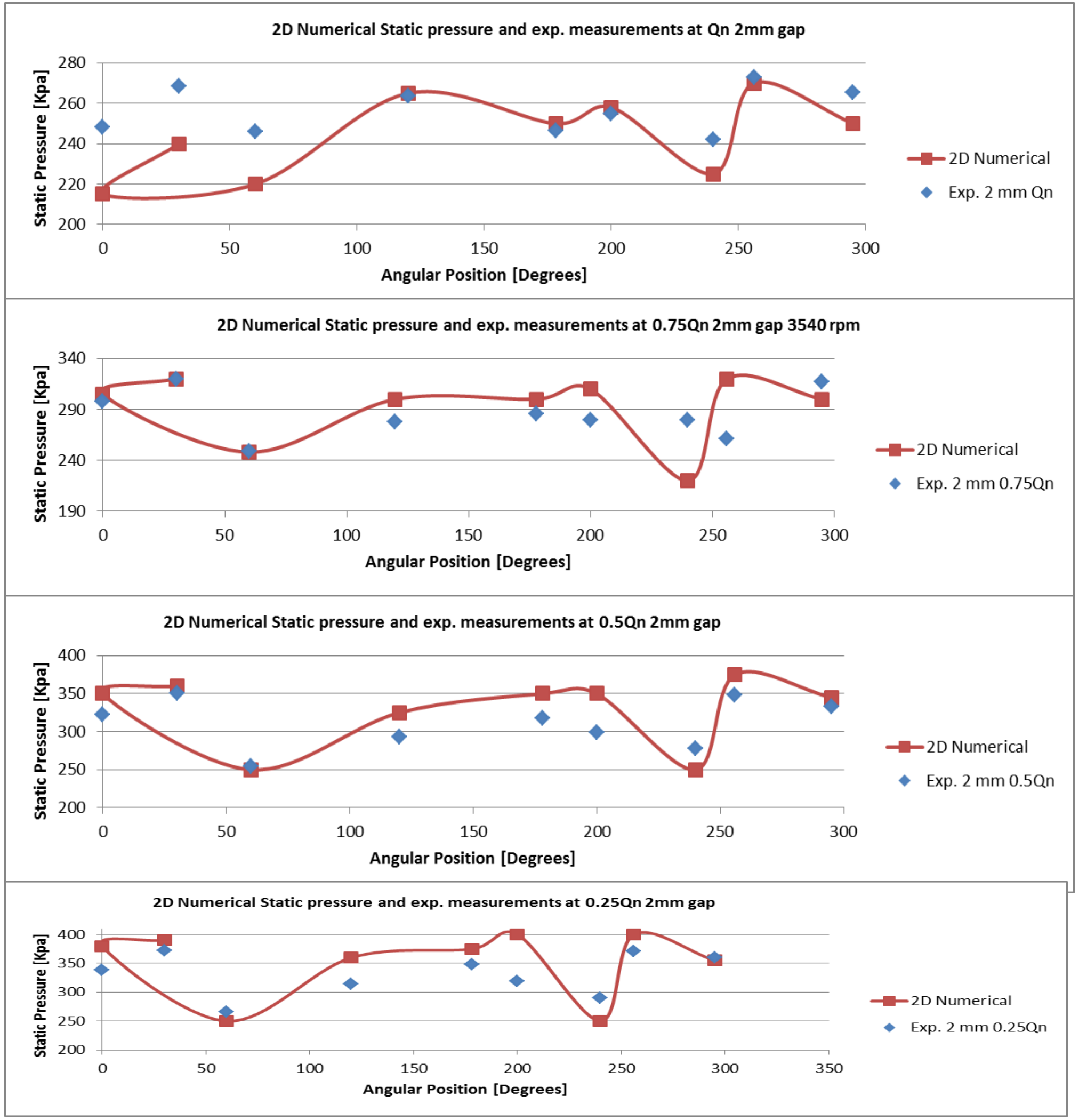

Fig. 8 
A 2D NUMERICAL AND EXPERIMENTAL INVESTIGATION ON THE PRESSURE FLUCTUATIONS INSIDE A DOUBLE VOLUTE CENTRIFUGAL PUMP AT THREE DIFFERENT RADIAL GAPS
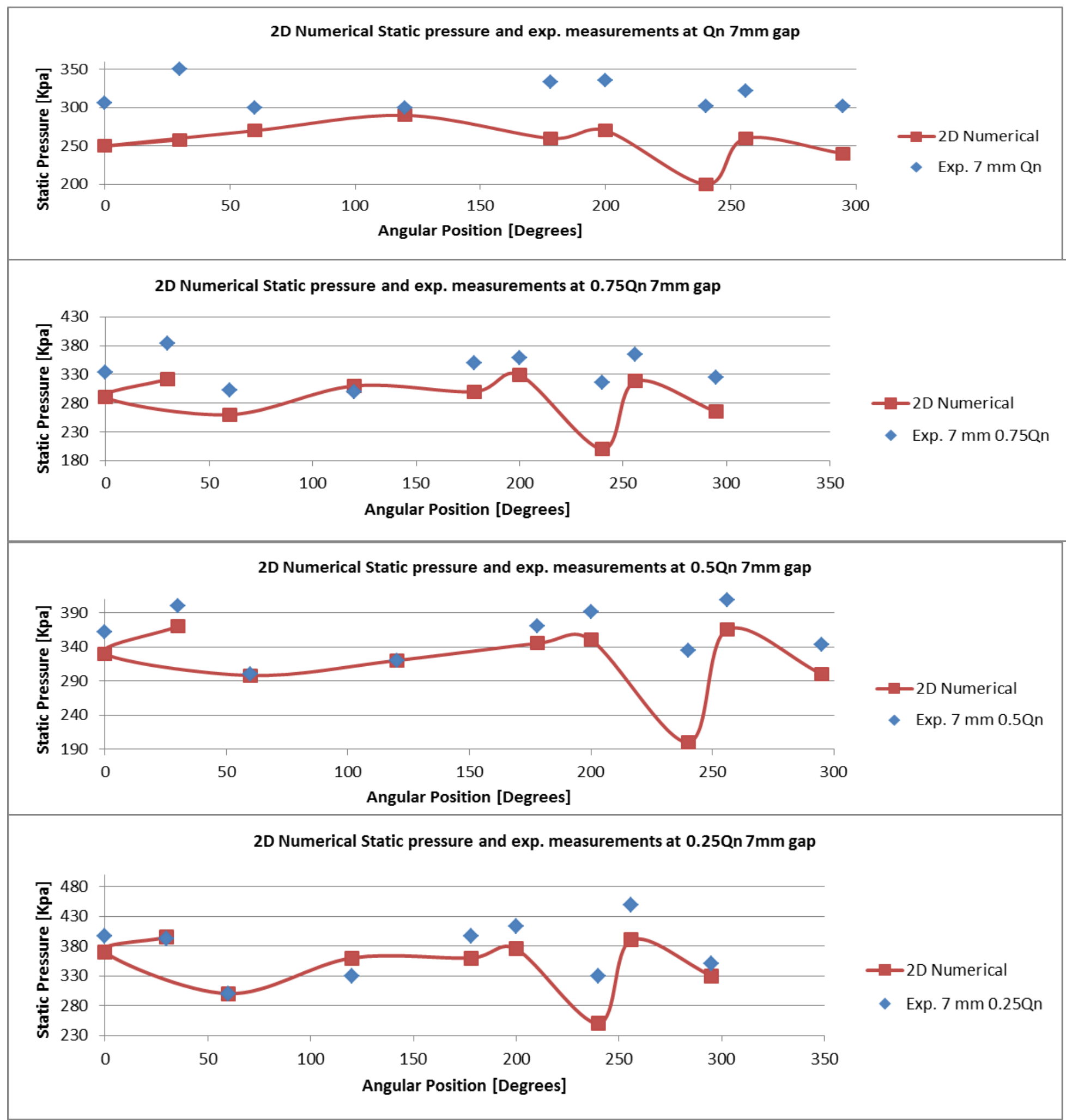

Fig.9 
From figures $(7,8$, and 9), we can see that the numerical results of the static pressure at the 3 radial gaps are consistent with the experimental results. We can conclude from this that the static pressure inside the pump has a $2 \mathrm{D}$ behavior and it is also constant in the axial direction because the numerical results are reoresent the static pressure values at the middle plane of the impeller and the experimental measurements were taken at $1 \mathrm{~mm}$ from the wall inside the pump.

\subsection{Pressure Fluctuations}

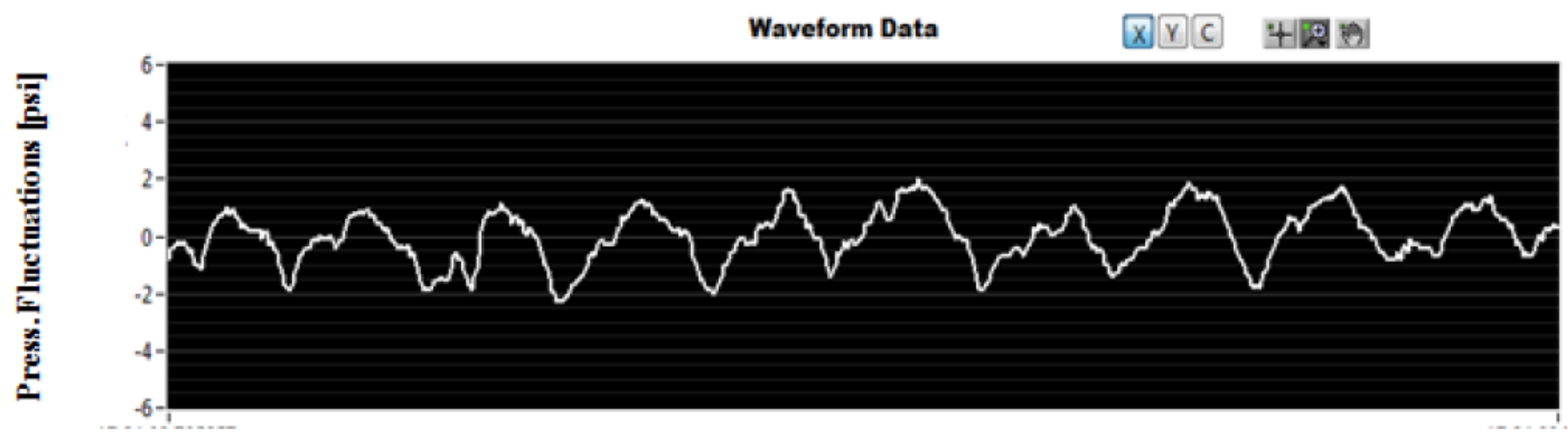

Fig.10 The experimental waveform of the pressure fluctuations at location 3 at Qn "The nominal flow rate" at $3.6 \mathrm{~mm}$ gap

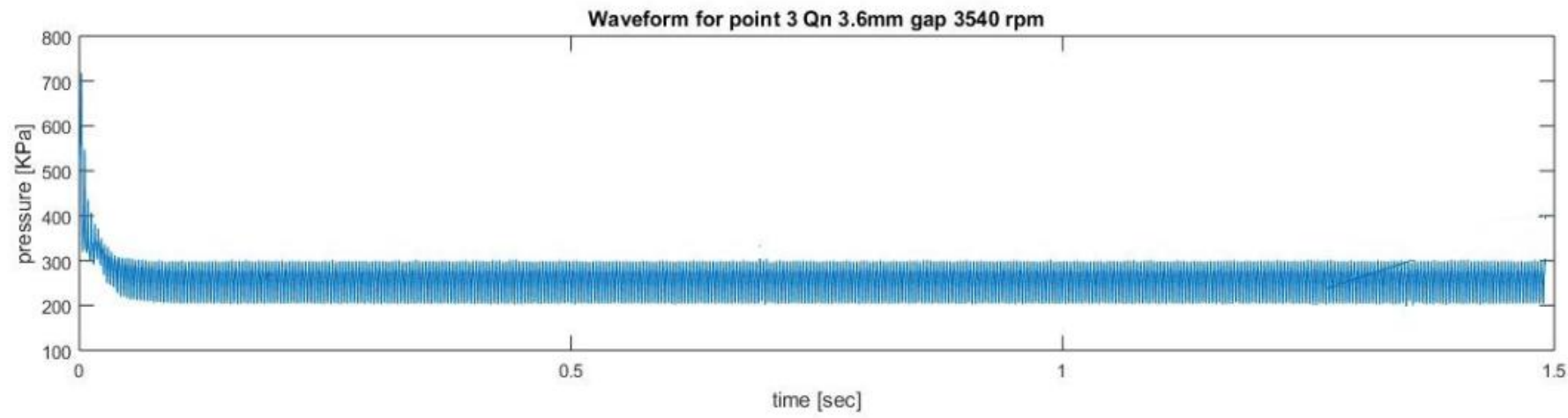

Fig.11 The numerical waveform of the pressure fluctuations at location 3 at Qn "The nominal flow rate"

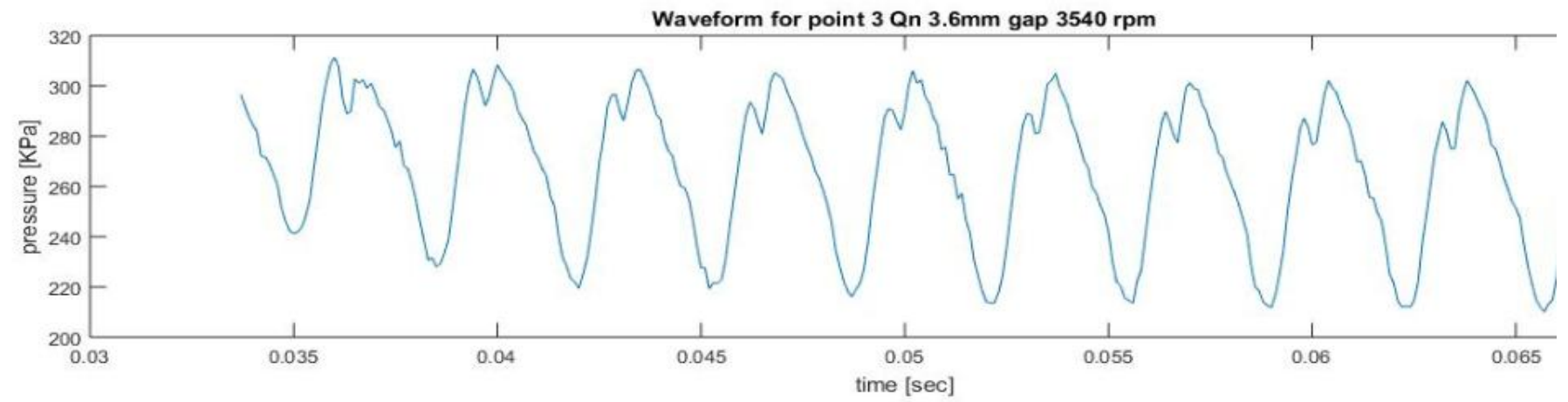

Fig.12 The numerical waveform of the pressure fluctuations at location 3 at Qn "The nominal flow rate"

Figures $(10,11$, and 12) show that the 2D numerical solution of the pressure fluctuations 
waveform is consistent with the experimental waveform at the same location and gap. The static pressure value is the average of the fluctuating values through the time. On the other hand, the 2D values of the amplitudes of the pressure fluctuations "peak-to-peak" are over estimated.

\section{Frequency Spectrum}

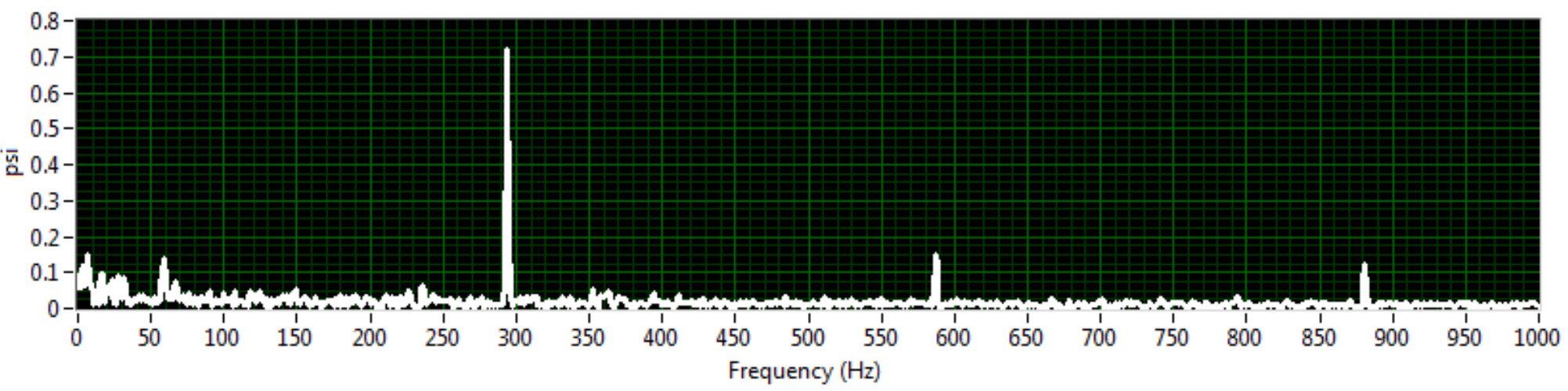

Fig.13 The experimental frequency spectrum at location 3 at Qn at gap $3.6 \mathrm{~mm}$ that shows the FFT magnitude

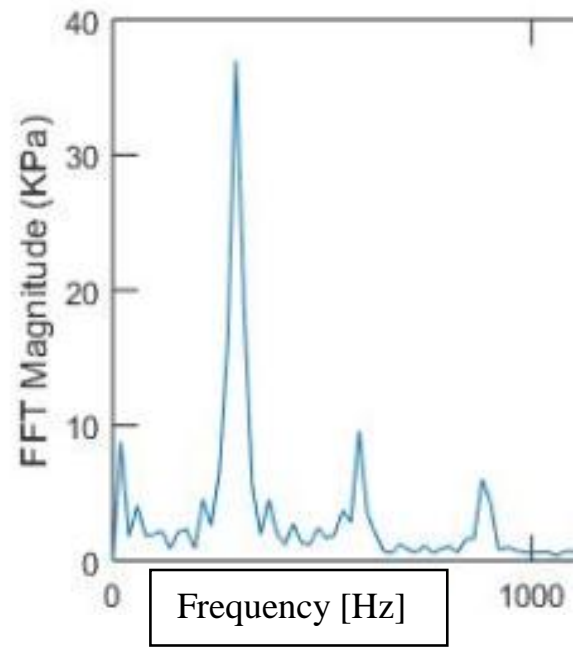

Fig.14 The 2D numerical FFT magnitude at location 3 at Qn at gap $3.6 \mathrm{~mm}$

Figures (13 and 14) show that the 2D numerical FFT magnitude is very high when we compare it with the experimental FFT value. The peak is at $1^{\text {st }}$ blade passing frequency BPF $(295 \mathrm{~Hz})$ experimentally and numerically. 


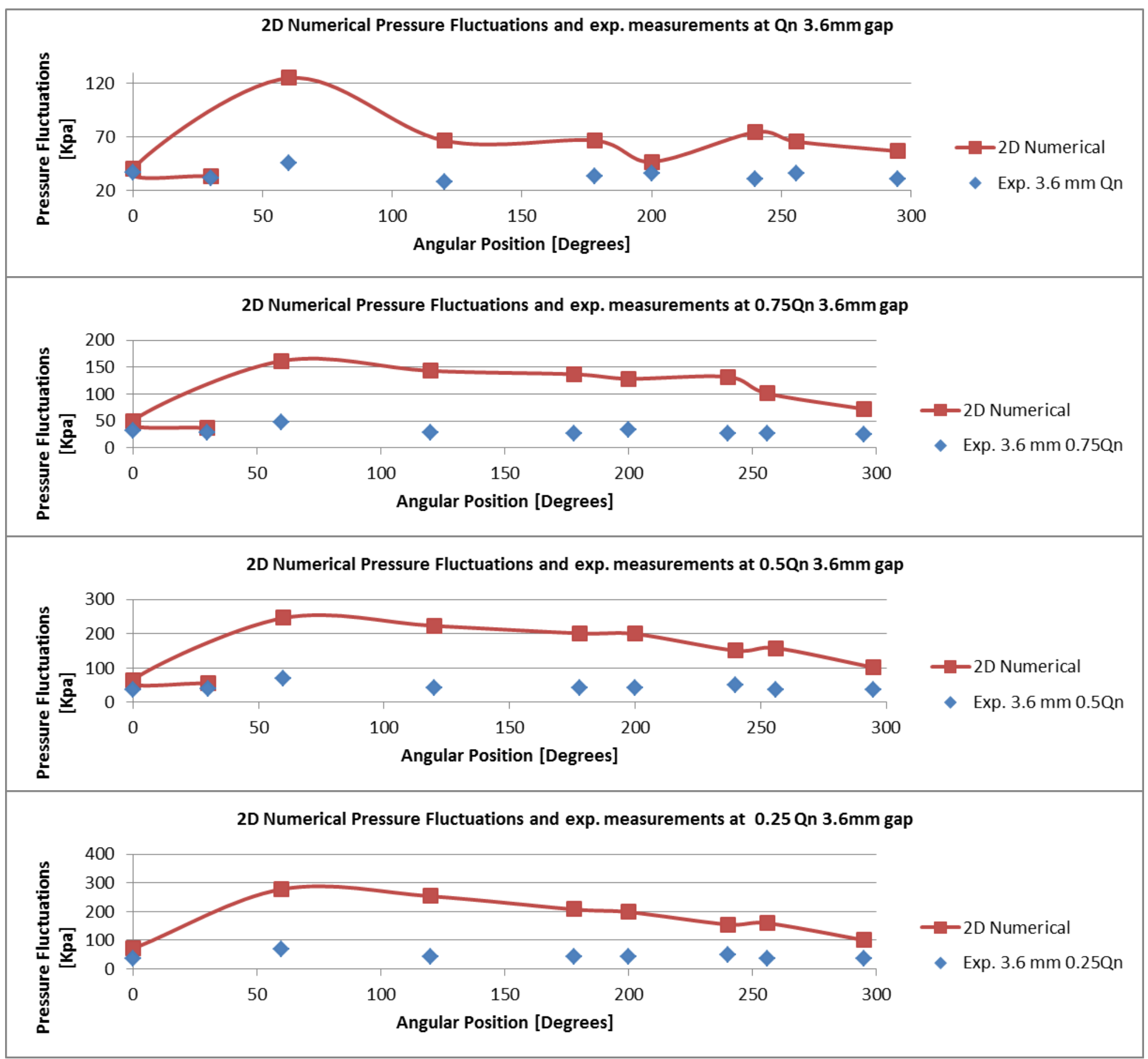

Fig.15 
A 2D NUMERICAL AND EXPERIMENTAL INVESTIGATION ON THE PRESSURE FLUCTUATIONS INSIDE A DOUBLE VOLUTE CENTRIFUGAL PUMP AT THREE DIFFERENT RADIAL GAPS
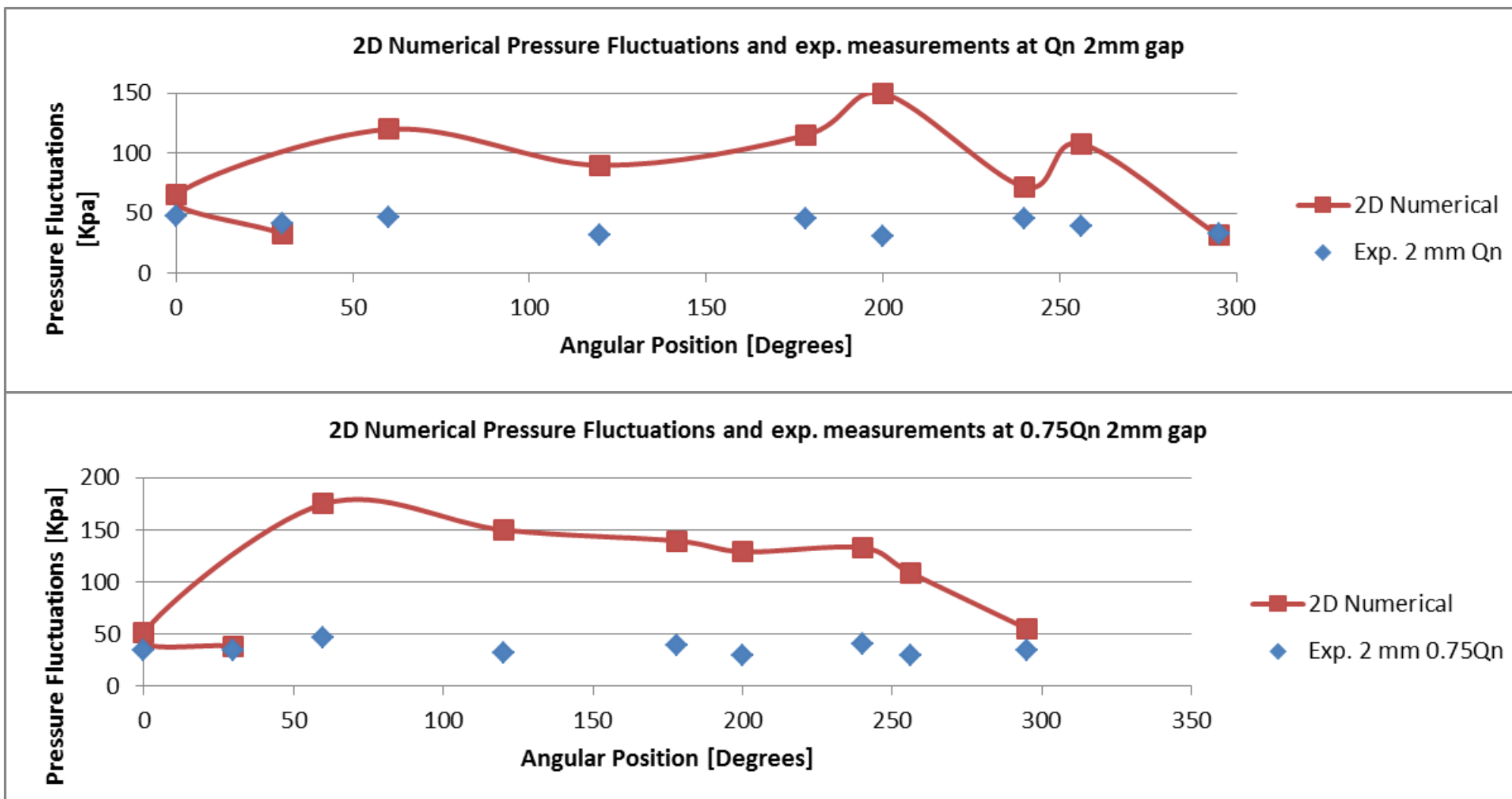

2D Numerical Pressure Fluctuations and exp. measurements at 0.5Qn 2mm gap

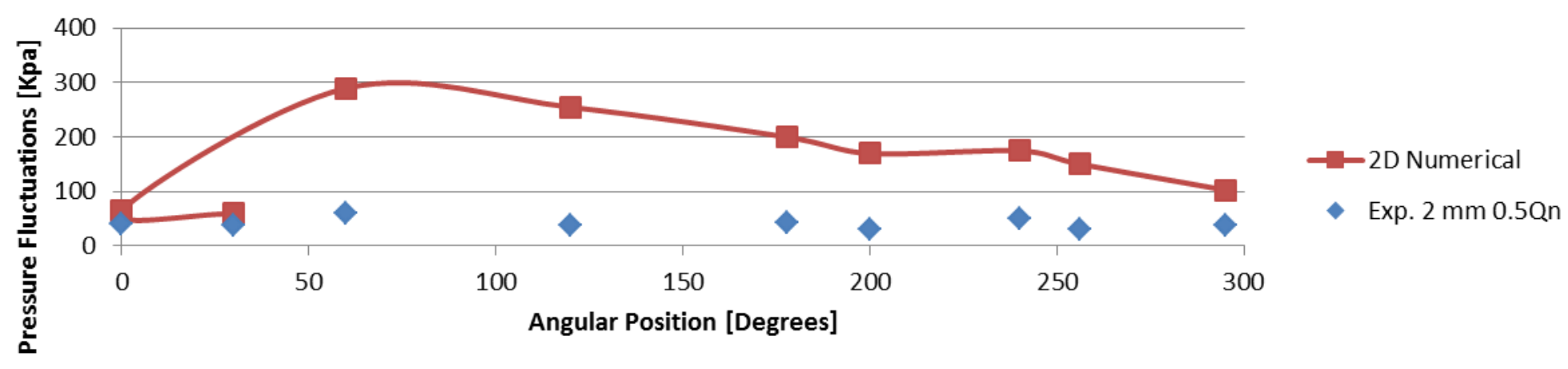

2D Numerical Pressure Fluctuations and exp. measurements at 0.25Qn $2 \mathrm{~mm}$ gap

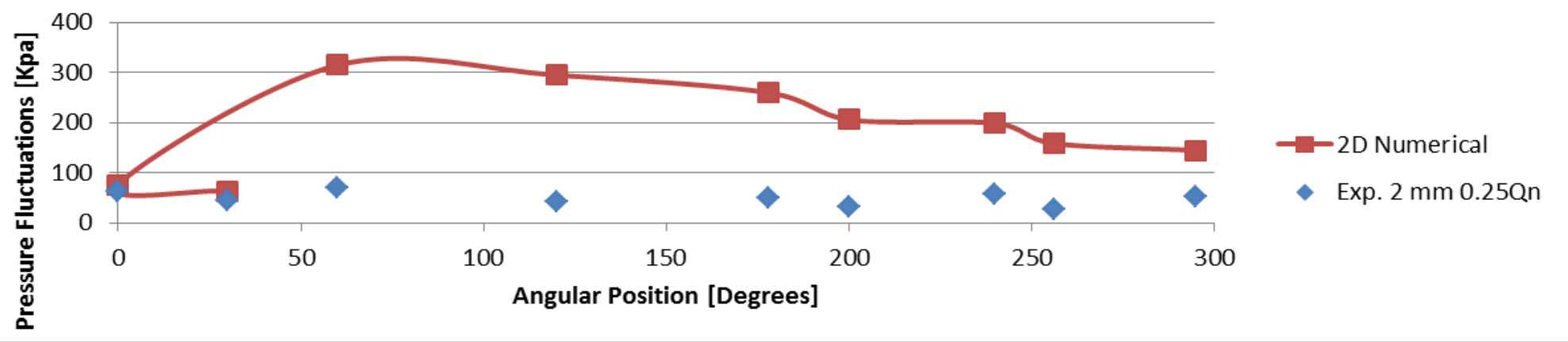

Fig.16 
A 2D NUMERICAL AND EXPERIMENTAL INVESTIGATION ON THE PRESSURE FLUCTUATIONS INSIDE A DOUBLE VOLUTE CENTRIFUGAL PUMP AT THREE DIFFERENT RADIAL GAPS
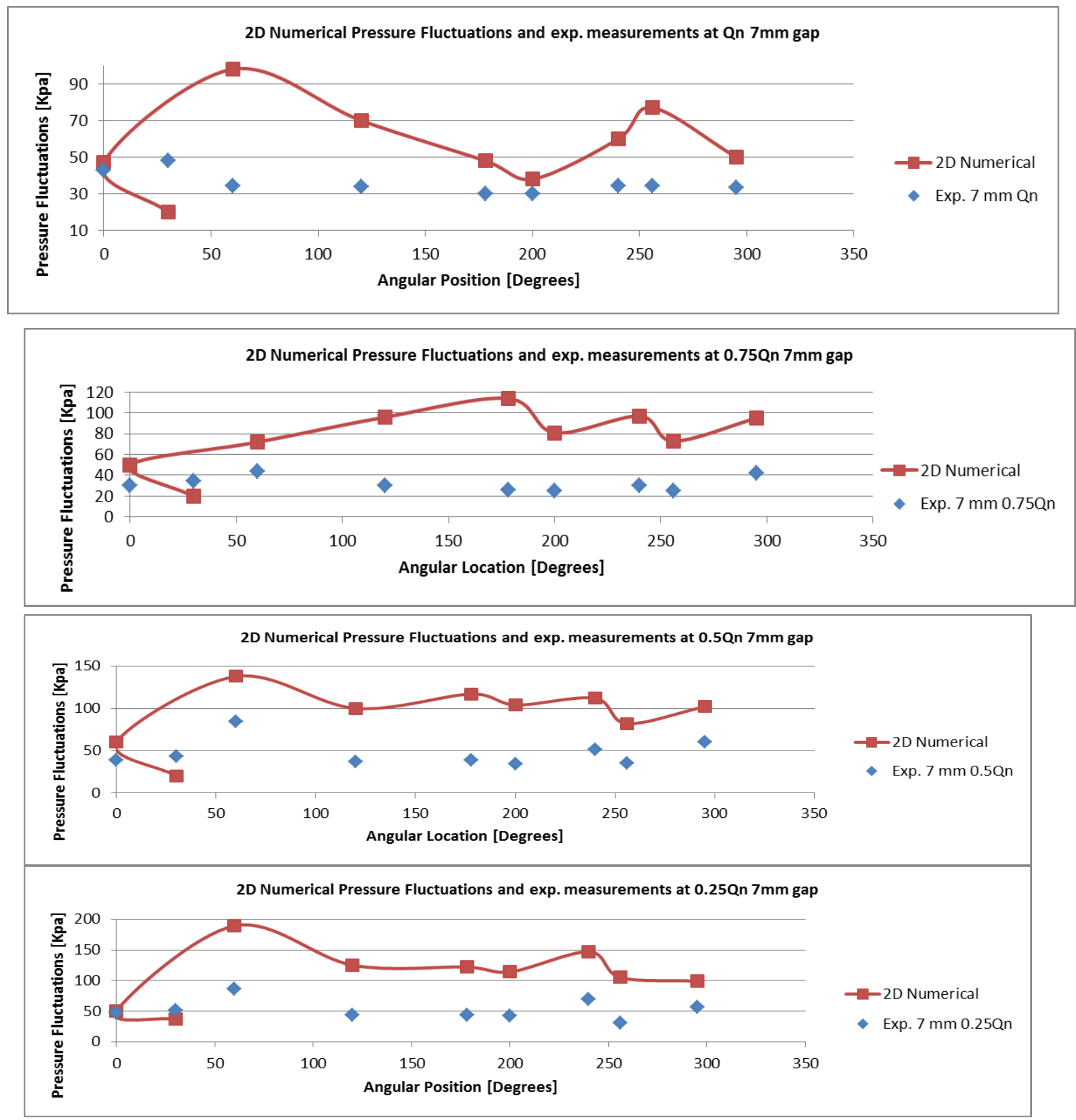

Fig. 17 
A 2D NUMERICAL AND EXPERIMENTAL INVESTIGATION ON THE PRESSURE FLUCTUATIONS INSIDE A DOUBLE VOLUTE CENTRIFUGAL PUMP AT THREE DIFFERENT RADIAL GAPS

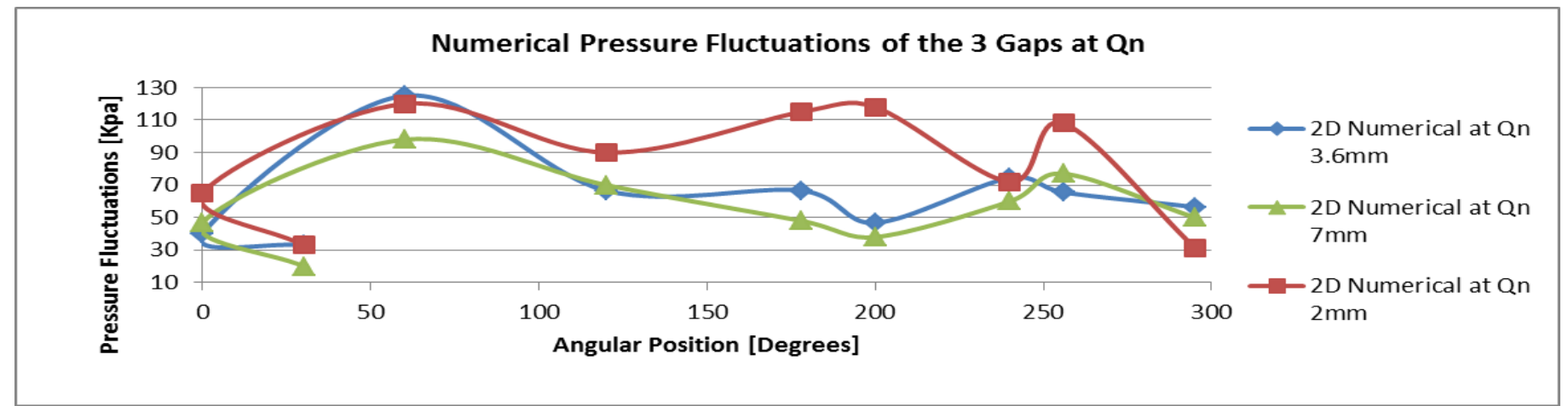

Numerical Pressure Fluctuations at 3 Gaps 0.75 Qn

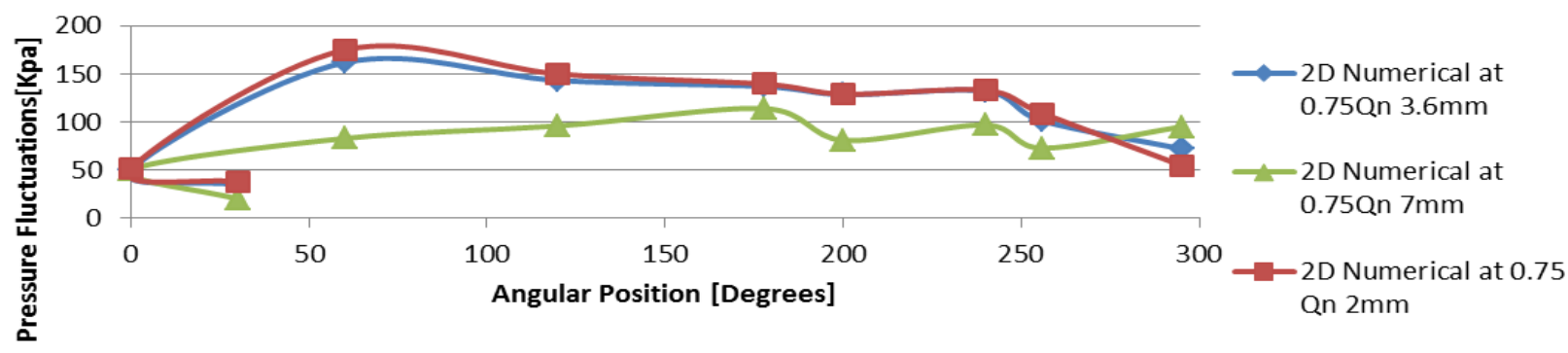

Numerical Pressure Fluctuations of the 3 Gaps at 0.5 Qn
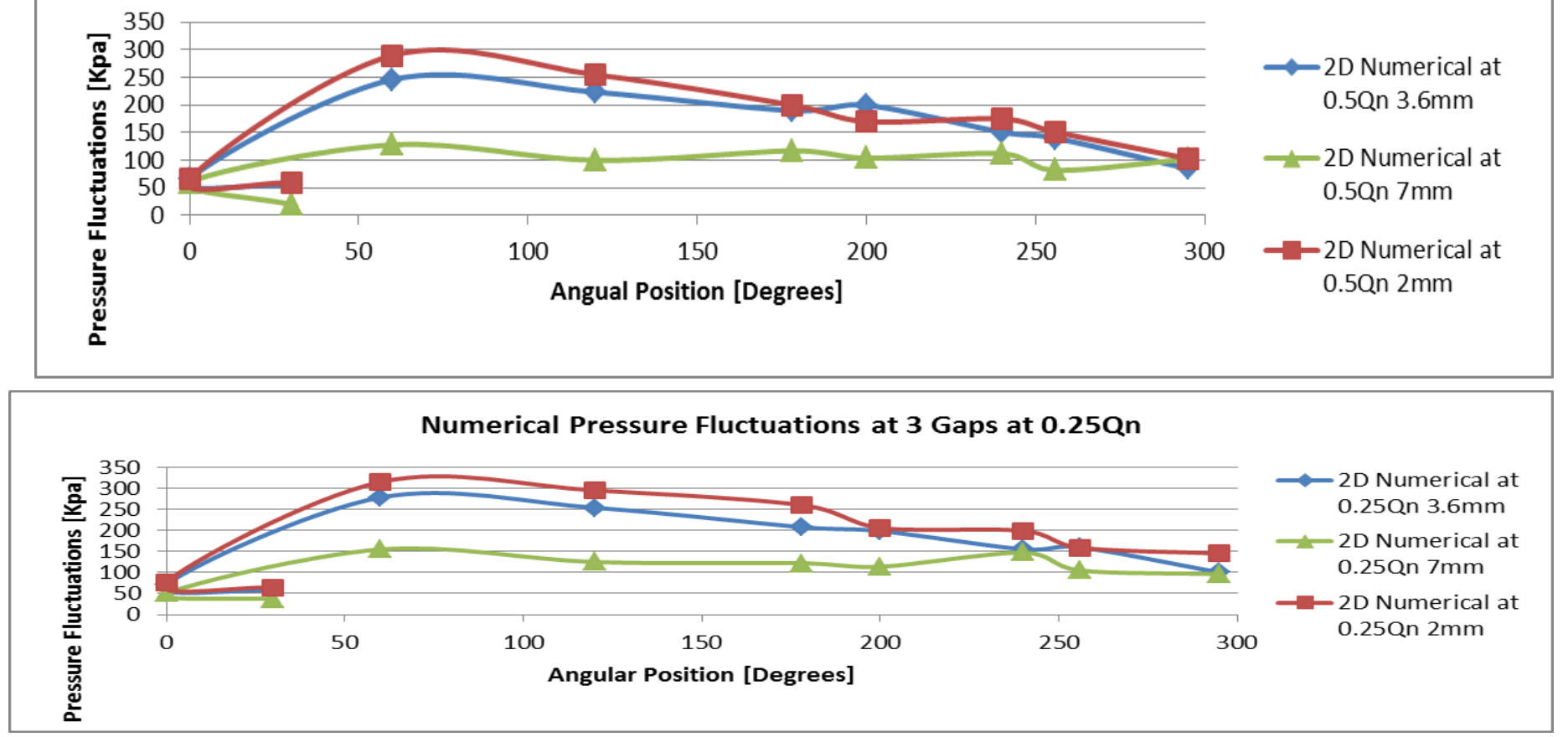

Fig. 18

Figures $(15,16$, and 17$)$ show the comparison between the 2D numerical pressure fluctuations results and the experimental pressure fluctuations at the three different radial gaps between the rotor and stator. The plots show that the numerical pressure fluctuations at the 3.6 and $2 \mathrm{~mm}$ gaps 
are very high. On the other hand, the 2D numerical fluctuations at $7 \mathrm{~mm}$ gap are lower than the other gaps but they are still higher than the experimental measurements to a high value. Also we can see that the presure fluctuations at a specific gap increase with decreasing the flow rate (offpeak) conditions and this is due to beig far away from the design point and this proves that at low flow rates especially $0.5 \mathrm{Qn}$ and $0.25 \mathrm{Qn}$, the pressure fluctuations at a specific gap will be higher than the pressure fluctuations at the nominal flow rate and generally it is preferred to work at the nominal flow rate or near it for the pumps. The experiments showed that the pressure fluctuations decreases at higher gaps "7 mm gap" and at lower gaps "2 $\mathrm{mm}$ " increases and become higher than the original gap and this was also proven numerically and figure 18 shows this. Figure 18 shows comparisons between the pressure fluctuations at a specific flow rate at the three different radial gaps and the lowest pressure fluctuations were at the highest gap "7mm". It was proven experimentally [1-5] that the $7 \mathrm{~mm}$ gap is the best solution for the vibrations and noise reduction and the numerical solutions gice a good agreement with this especially that the $7 \mathrm{~mm}$ gap gives the lowest pressure fluctuations experimentally and numerically which enhances the pump balance during the operation. And this is a conclusion that at higher gaps"7mm", the flow inside the pump become less unsteady but it is still full turbulent but the noise level is accepted [1].

\section{The Performance Curves}

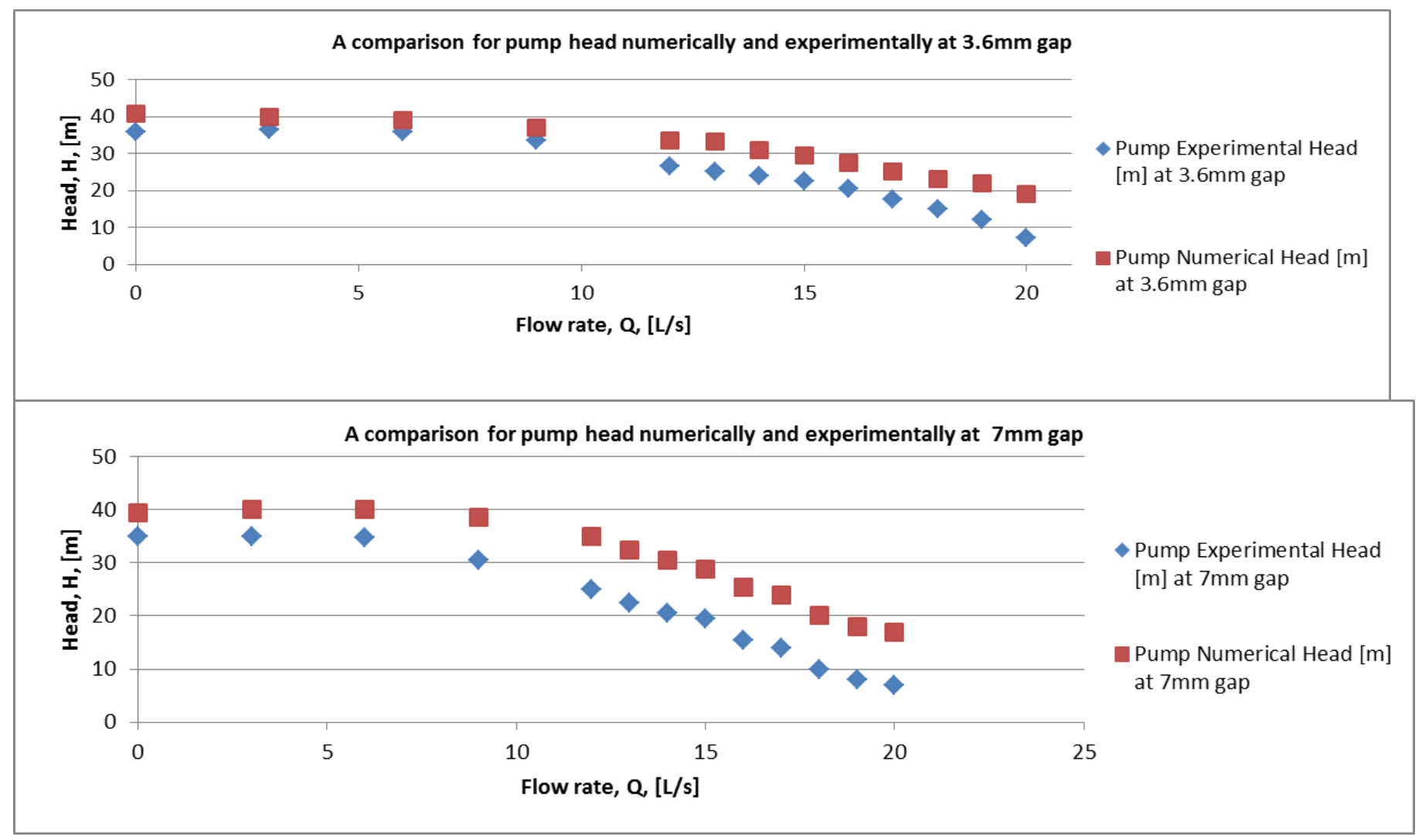

Fig.19 
A 2D NUMERICAL AND EXPERIMENTAL INVESTIGATION ON THE PRESSURE FLUCTUATIONS INSIDE A DOUBLE VOLUTE CENTRIFUGAL PUMP AT THREE DIFFERENT RADIAL GAPS

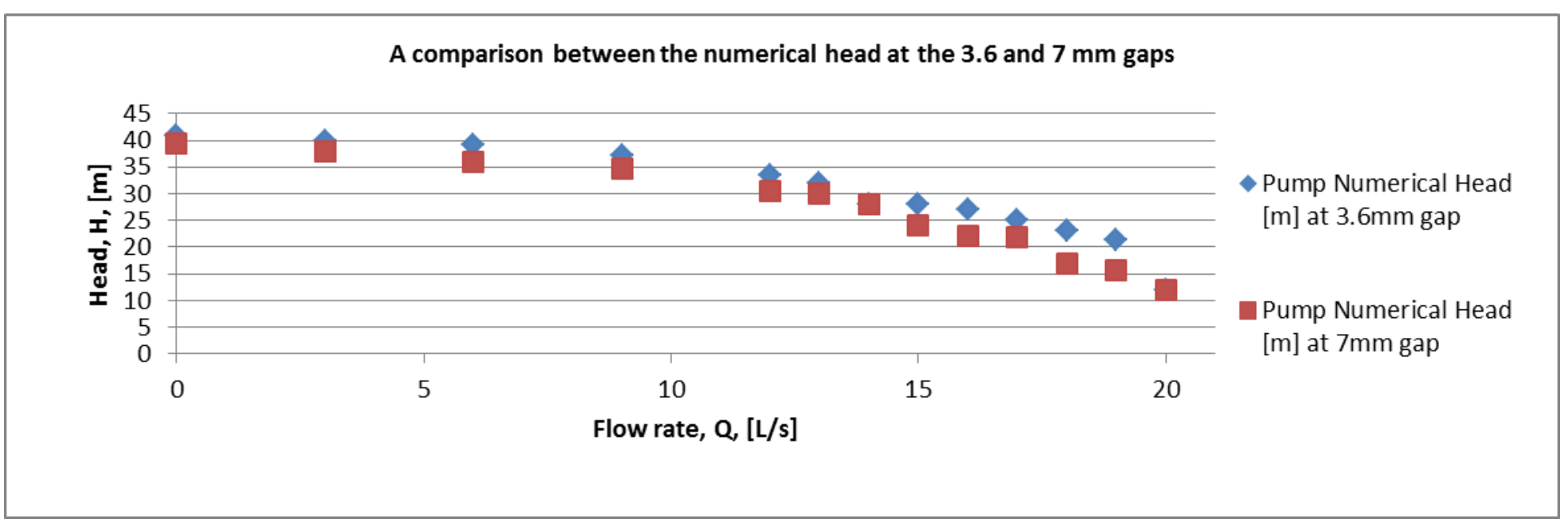

Fig.20

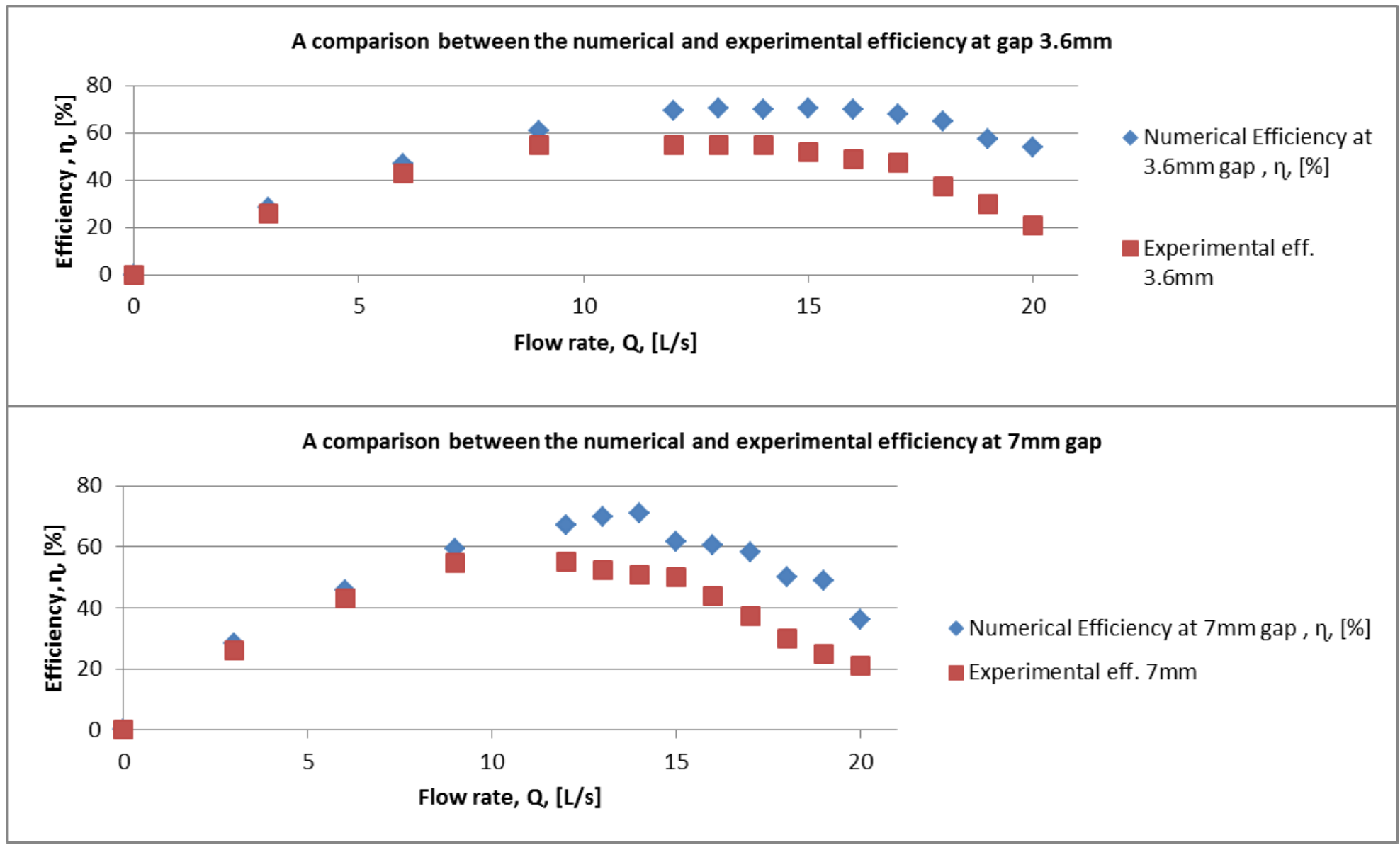

Fig. 21

A comparison between the numerical efficiency at $3.6,7 \mathrm{~mm}$ gaps

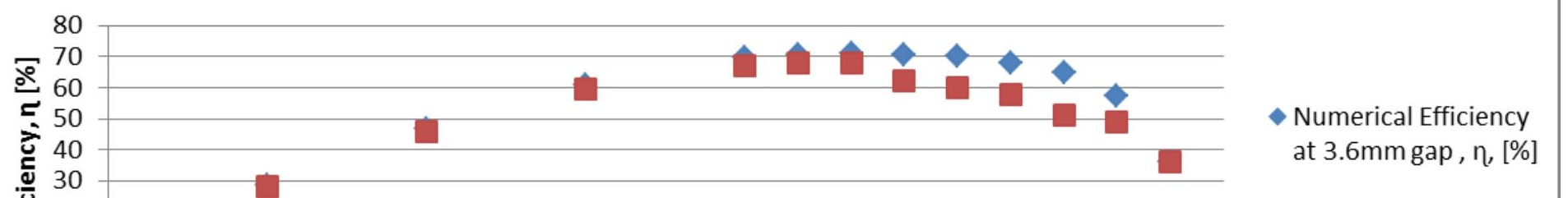


Fig.22

Figure (19) shows that the 2D numerical total head for the gaps 3.6 and $7 \mathrm{~mm}$ is over estimated and this is due to the nature of the flow inside the pump is highly $3 \mathrm{D}$ and the $2 \mathrm{D}$ simulations do not take this nature into consideration especially the inlet pipe is predicted to have an effect on the head, and the 2D model presents the inlet pipe just as a circle not a 3D cylinder. Figure (20) shows a comparison between the numerical total head between the 3.6, and $7 \mathrm{~mm}$ gaps, the total head at $7 \mathrm{~mm}$ gap is lower than the $3.6 \mathrm{~mm}$ gap total head due to the volute tongue trimming which affected the performance of the pump but this effect is considered acceptable experimentally and numerically because the pump is still gives the required head for its function especially at flow rates lower than the nominal flow rate[15]. Also, figure (21) shows a comparison between the numerical and experimental efficiency and the over estimation of the numerical results is also due to the $2 \mathrm{D}$ simulations which are not accurate enough to simulate the 3D high turbulent behaviour of the flow inside the pump. Figure (22) shows a comprison between the 2D numerical efficiency at the 3.6, and $7 \mathrm{~mm}$ gaps and we can see that the difference between them is not high especially at low flow rates and this was proven by the researchers experimentally [1-5]. There is no need to study the performance curves of the $2 \mathrm{~mm}$ gap becasue it was concluded that it increases the pressure fluctuations and it is the worst geometry modification. So, the best solution for the vibration and noise reduction is the $7 \mathrm{~mm}$ gap "the highest gap" .

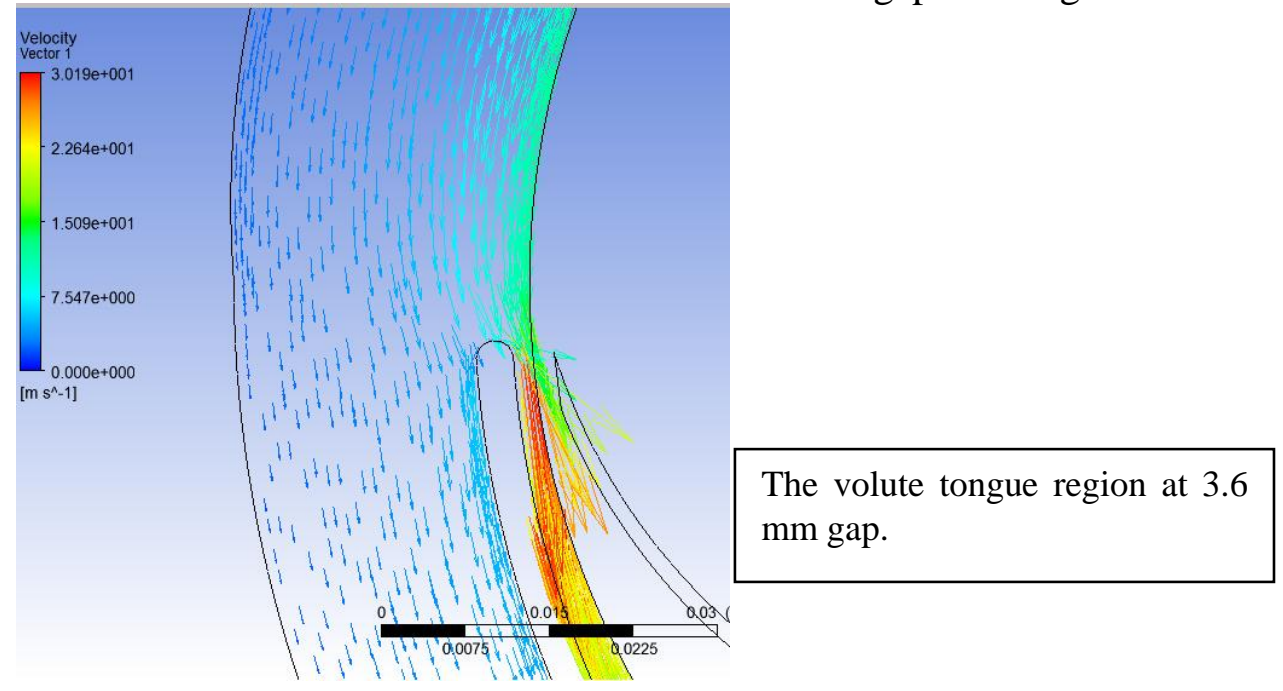




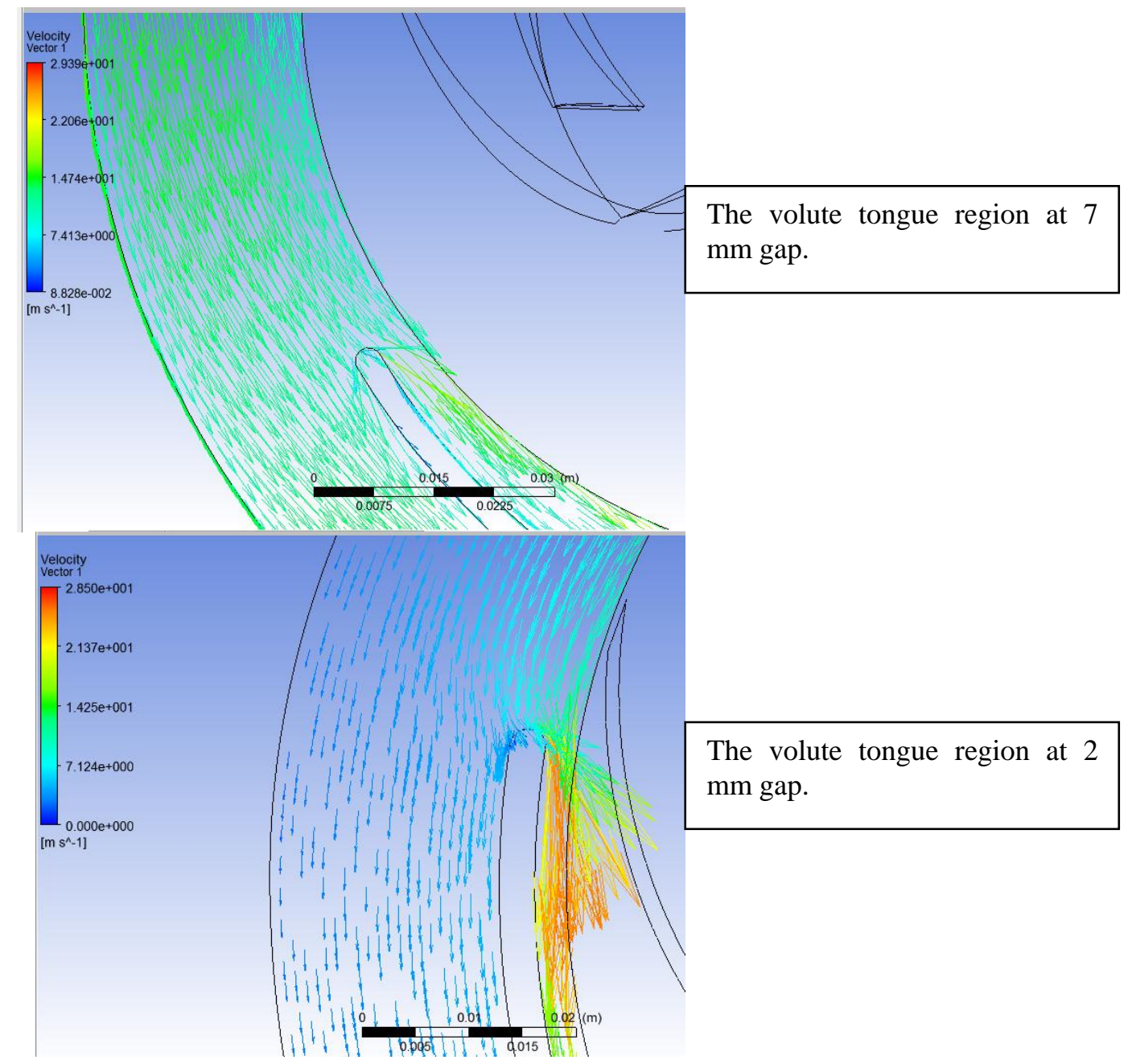

Figure 23

Figure (23) shows the velocity vectors at the three gaps. We can see that at the highest gap, the flow is more uniform and less unsteady than the the other two lower gaps due to the volute tongue trimming. On the other hand, at the lowest gap $2 \mathrm{~mm}$, the flow is highly disturbed by the narrow gap between the impeller and the volute tongue.

\section{CONCLUSION}

- It is clear that the numerical simulations are a very useful tool to understand the behaviour of the flow inside centrifugal pumps but 3D simulations are required for more accurate results.

- The numerical results of the static pressure give a good agreement with the experimental results at the three different gaps.

- The numerical results of the pressure fluctuations are very high if we compare them with the experimental results due to the simplicity of the 2D simulations that do not take the 3D high turbulent flow behaviour into consideration. On the other hand, the numerical results prove that to decrease the vibrations and noise of the pump, increeasing the gap between the rotor and stator is the best solution because this decreases the pressure fluctuations that are responsible for generating the forces on the impeller which cause 
unbalance and also at the highest gap the rotor stator interaction becomes lower than the other lower gaps.

- The preformance plots of the 3.6 , and $7 \mathrm{~mm}$ gaps prove that increasing the gap to $7 \mathrm{~mm}$ does not affect the pump performance greatly and the values of the total head and the efficiency are accepted experimentally especially after seeing the pressure fluctuations decrease at the $7 \mathrm{~mm}$ gap by $20 \%$ to $60 \%$ depending on the flow rate and location inside the pump [2] but we predict that the 3D numerical simulations will be more accurate.

\section{REFERENCES}

[1] AtiaKhalifa, Amro Al-Qutub and YehiaKhulief, "Resolving High Flow Induced Vibrations", WORLD PUMPS December 2010.

[2] A. Khalifa, R. Ben-Mansour, and A. Al-Qutub, " The Effect of Radial Gap on Pressure Field in a Double Volute Boiler Feed Pump" 7th International Conference on Computational Heat and Mass Transfer (2009).

[3] Atia E. Khalifa, Amro M. Al Qutub, and Rached Ben- Mansour "Study of pressure fluctuations and induced vibration at blade passing frequencies of a double volute pump"(2009).

[4] A.Al-Qutub, A. Khalifa, and Y. Khulief, "Experimental investigation of the effect of radial gap and impeller blade exit on flow -induced vibration at the blade-passing frequency in a centrifugal pump" International Journal of Rotating Machinery. DOI: 10.1007/s13369-0110119-8.

[5] Atia E. Khalifa, Performance and vibration of a double volute centrifugal pump -effect of impeller trimming, International Mechanical Engineering Congress\&Exposition,IMECE2014.

[6] Kean Wee Cheah, Thong See Lee and Sonny H. Winoto, "Unsteady Analysis of ImpellerVolute Interaction in Centrifugal Pump" International Journal of Fluid Machinery and Systems. DOI: 10.5293/IJFMS.2011.4.3.349.

[7] José González and Carlos Santolaria, " Unsteady Flow Structure and Global Variables in a Centrifugal Pump" Journal of Fluids Engineering. ASME 2006. DOI: 10.1115/1.2234782.

[8] Houlin Liu, Xianfang Wu, and Minggao Tan, "Numerical Research on Hydraulically Generated Vibration and Noise of a Centrifugal Pump Volute with Impeller Outlet Width Variation" Variation. Mathematical Problems in Engineering 2014. DOI:10.1155/2014/620389.

[9] Mohan LamloumiHedi, KanfoudiHatem, ZgolliRidha , " Numerical Analysis of the Flow Through in Centrifugal Pumps" International Journal of Thermal Technologies 2012.

[10] A. G. Backman, M.J. Cervantes, and A.R. Zobeiri " CFD validation of pressure fluctuations in a pump turbine"

[11] Xiaoran Zhao, Zhengwei Wang, Yexiang Xiao, Yongyao Luo, Lei Cao " Unsteady Flow and Pressure Pulsation Characteristics Analysis of Rotating Stall in Centrifugal Pumps under Off Design Conditions" International Symposium on Transport Phenomena and Dynamics of Rotating Machinery Hawaii, Honolulu April 10-15, 2016.

[12] Lei Cao, Zhengwei Wang, Yexiang Xiao, and Yongyao Luo, " Numerical Investigation of Pressure Fluctuation Characteristics in a Centrifugal Pump with Variable Axial Clearance". International Journal of Rotating Machinery 2016.

[13] Houlin Liu, Xianfang Wu, and Minggao Tan, "Numerical Investigation of the Inner Flow in a Centrifugal Pump at the Shut-Off Condition". JOURNAL OF THEORETICAL AND APPLIED MECHANICS 51, 3, pp. 649-660, Warsaw 2013.

[14] PEI Ji, WANG Wenjie, and YUAN Shouqi, " Statistical analysis of pressure fluctuations during unsteady flow for low specific speed centrifugal pumps", Research Center of Fluid Machinery Engineering and Technology, Jiangsu University, Zhenjiang 212013, China () Central South University Press and SpringerVerlag Berlin Heidelberg 2014. DOI: 10.1007/s11771-014-2032-2. 
[15] Alfred Fontanals, Alfredo Guardo, Miguel Coussirat and Eduard Egusquiza " Numerical Study of the Fluid - Structure Interaction in the Diffuser Passage of a Centrifugal Pump" IV International Conference on Computational Methods for Coupled Problems in Science and Engineering COUPLED PROBLEMS 2011 M. Papadrakakis, E. Oñate and B. Schrefler (Eds).

[16] R. Spence and J. Amaral-Teixeira, "A CFD Parametric Study of Geometrical Variations on the Pressure Pulsations and Performance Characteristics of a Centrifugal Pump" Computers \& Fluids 38 (2009) 1243-1257. DOI: 10.1016/j.compfluid.2008.11.013.

[17] R. Spence , J. Amaral-Teixeira, "Investigation Into Pressure Pulsations in a Centrifugal Pump Using Numerical Methods Supported by Industrial Tests".Computers\& Fluids (2007) .

[18] C. G. Rodriguez, E. Egusquiza I. F. Santos, "Frequencies in the Vibration Induced by the Rotor Stator Interaction in a Centrifugal Pump Turbine". Journal of Fluids Engineering. Transaction of the ASME. 2007. DOI: 10.1115/1.2786489.

[19] ShijieGuo and Yoshiyuki Maruta "Experimental Investigations on Pressure Fluctuations and Vibration of the Impeller in a Centrifugal Pump with Vaned Diffusers" JSME International Journal series B. Vol. 48, No. 1, 2005.

[20] M. Zhang M. and Tsukamoto H., "Unsteady Hydrodynamic Forces Due to Rotor-Stator Interaction on a Diffuser pump with Identical Number of Vanes on the Impeller and Diffuser, Journal Of Fluids Engineering, Transactions of The ASME, Vol. 127, July 2005, pp 743-751. DOI: $10.1115 / 1.1949640$.

[21] Hong Wang and Hiroshi Tsukamoto " Experimental and Numerical Study of Unsteady Flow in a Diffuser Pump at Off-Design Conditions" Journal of Fluids Engineering copyright by ASME 2003. DOI: 10.1115/1.1603305.

[22] Jose' Gonza'lez, Joaqui'nFerna'ndez, Eduardo Blanco, Carlos Santolaria, "Numerical Simulation of the Dynamic Effects Due to Impeller-Volute Interaction in a Centrifugal Pump. JOURNAL OF FLUIDS ENGINEERING 2002. DOI: 10.1115/1.1457452.

[23] H. Wang and H. Tsukamoto " Fundamental Analysis on Rotor-Stator Interaction in a Diffuser Pump by Vortex Method" Journal of Fluids Engineering Copyright (C) 2001 by ASME DECEMBER 2001, Vol. 123 / 737. DOI: 10.1115/1.1413242.

[24] Blanco-Marigorta, Eduardo; Fernández-Francos, Joaquín González-Pérez, José; SantolariaMorros, Carlos. " Numerical Flow Simulation in a Centrifugal Pump with Impeller - Volute Interaction"Proceedings of ASME FEDSM'00 ASME 2000 Fluids Engineering Division Summer Meeting June 11-15, 2000, Boston, Massachusetts .Copyright by ASME 2000.

[25] Kevin A. Kaupert and Thomas Staubli " The Unsteady Pressure Field in a High Specific Speed Centrifugal Pump Impeller- Part I: Influence of the Volute" Journal of Fluids Engineering Copyright (C) 1999 by ASWIE SEPTEMBER 1999, Vol. 121 / 621.

[26] M. Morgenroth and D. S. Weaver, "Sound Generation by a Centrifugal Pump at Blade Passing Frequency", Journal of Turbomachinery | Volume 120 | Issue 4, 1998.

[27] R. Dong, S. Chu and J. Katz " Effect of Modification to Tongue and Impeller Geometry on Unsteady Flow, Pressure Fluctuations, and Noise in a Centrifugal Pump". Journal of Turbomachinery of the ASME 1997.

[28] John P. Pembroke, Eugene P. and David E. Littlefield" CFD Analysis of a Double Suction Cooling Water Pump" Proceedings of the 15th international pump users symposium.

[29] Jorge L. Parrondo-Gayo, Jose' Gonza'lez-Pe'rez, and Joaqui'nFerna'ndez-Francos " The Effect of the Operating Point on the Pressure Fluctuations at the Blade Passage Frequency in the Volute of a Centrifugal Pump" Journal of fluids engineering 784 / Vol. 124, SEPTEMBER 2002 Copyright (C) 2002 by ASME Transactions of the ASME. DOI: $10.1115 / 1.1493814$.

[30] J.L. Parrondo, J. Fernandez, c. Santolaria\& j. Gonzalez, "Measurements in the Dynamic Pressure Field of the Volute of a Centrifugal Pump" E. Cabrera et al. (eds.), Hydraulic Machinery and Cavitation, 401-410. 1996 Kluwer Academic Publishers. 
[31] D. Croba and J. L. Kueny "Numerical Calculation of 2D, Unsteady Flow in Centrifugal Pumps: Impeller and Volute Interaction". International Journal for Numerical Methods In Fluids. 1996.

[32] Ken Atkins and Jim Tison, "Solving Pulsation Induced Vibration Problems in Centrifugal Pumps" Pumps and Systems Magazine, January 1993.

[33] R. D. Flack, S. M. Miner, and R. J. Beaudoin," Turbulence Measurements in a Centrifugal Pump With a Synchronously Orbiting Impeller". Journal of Turbomachinery. ASME1992.

[34] N. Arndt, A. J. Acosta, C. E. Brennen, T. K. Caughey "Experimental Investigation of Rotor-Stator Interaction in a Centrifugal Pump With Several Vaned Diffusers" California Institute of Technology, Pasadena, CA 91125. Journal of Turbomachinery. Transaction of ASME. 98/Vol.112 January 1990.

[35] N. Arndt, a. J. Acosta, c. E. Brennen, t. K. Caughey, "Rotor-Stator Interaction in a Diffuser Pump", Journal of Turbomachinery. Transaction of The ASME.1989. 